\title{
المهارات اللازمة لتطوير المحاضرات الإكترونية وإدارتها من بعد لاى أعضاء هيئة التدريس بجامعة سبها الليبية
}

\author{
إعداد \\ أيوب سالم محمد أحمد الحاج على \\ باحث ماجستير تخصص تكنولوجيا التعليم
}

قسم تكنولوجيا التعليم - كلية التربية - جامعة دمياط

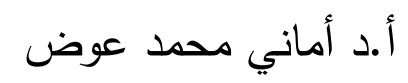

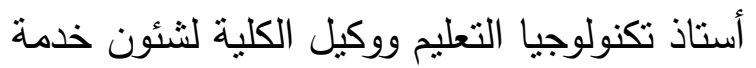
المجتمع وتتمية البيئة ومدير مركز إنتاج

المقررات الإكترونية بجامعة دمياط
أ. أند الثحات سعد عتمان

أستاذ تكنولوجيا التعليم ووكيل الكلية لنشئون التعليم والطلاب،ومدير وحدة التعليم

الإلكترونى بجامعة دمياط

2019 
المهار ات اللازمة لتطوير المحاضرات الإلكترونية و إدارتها من بعد لدى أعضاء هيئة التدريس بجامعة سبها الليبية مستخلص البحث: - n هدف البحث الحالى إلى التوصل لقائمة بمهارات تطوير المحاضرات الإلكترونية وإدراتها من بعد لاى أعضاء هيئة التدريس بجامعة سبها الليبية، وللتحقق من هذا الهدف قام الباحثون باعداد استبانة

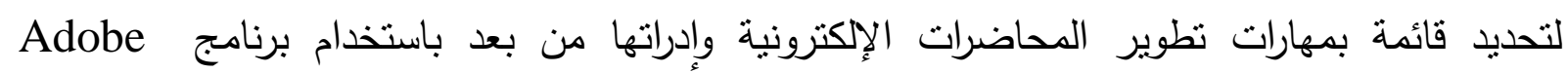
connect

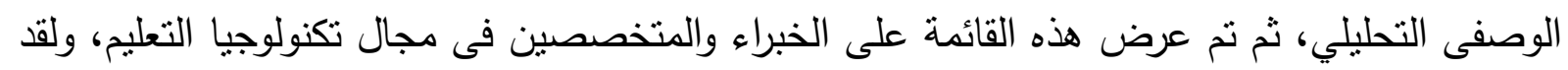
تكونت عينة البحث من خمسة عشر محكمًا من المتخصصين فى مجال تكنولوجيا التعليم، ثم قام أمثاء

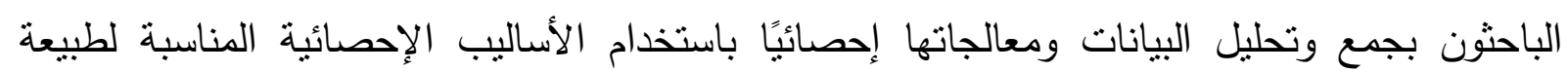
البحث، وأثنارت نتائج البحث إلى اتفاق السادة المحكمين على أهية كل من المهارات الرئيسة والفرعية.

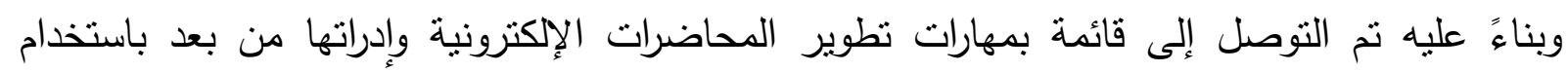
برنامج Adobe connect والتى تكونت فى صورتها النهائية من (3) مهارات رئيسة، و و(22) مهارة فرعية

$$
\text { الكلمات المفتاحية: المهارة - المحاضرة الإلكترونية - التعلم من بعد }
$$




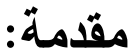

لقد أحدثت التطورات التي شهدتها مجالات تقنية المعلومات والاتصالات تحوّلات ملحوظة، أدت إلى ظهور آليات حديثة في طرق اكتساب المعارف والمهارات، وفي وسائل نقلها وإستراتيجيات نوليدها،

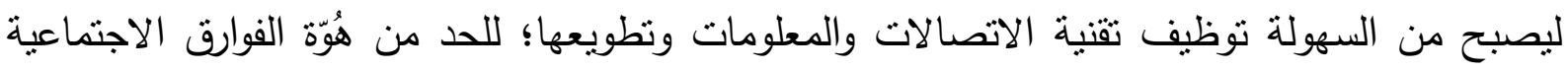
والثقافية بين المتعلمين، وتخطي قيود الزمان والمكان ونُدرة الموارد البشرية.

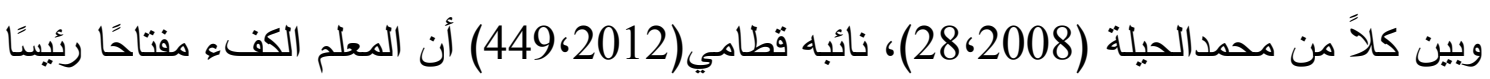

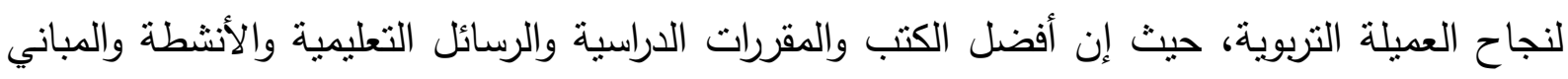

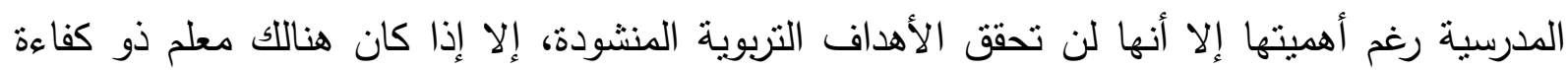

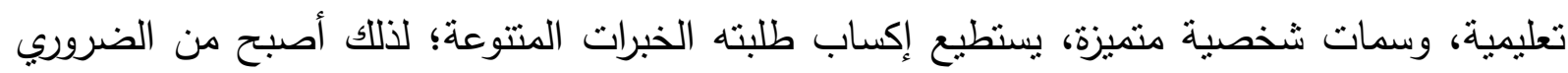

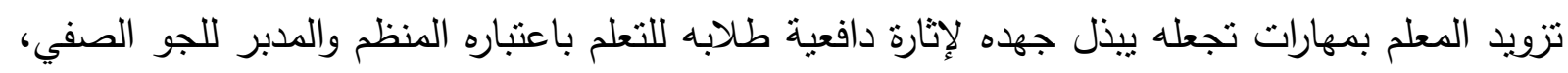

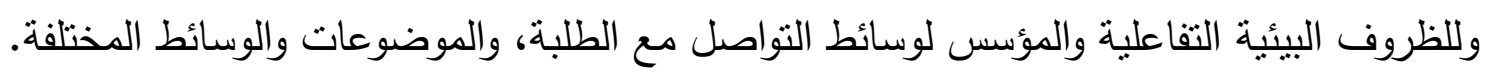
وتُعد المحاضرة من الإستراتيجيات الثائع استخدامها في التشريس، حيث يقوم المحاضر بإعداد

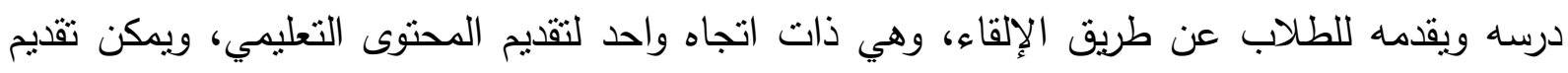

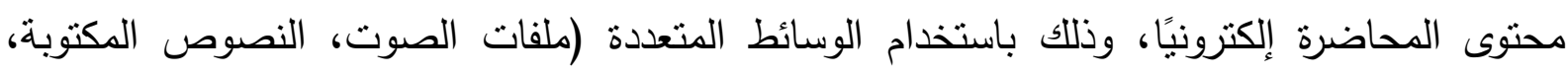

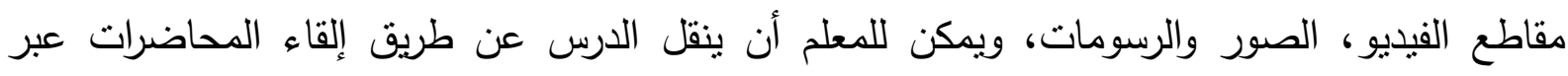

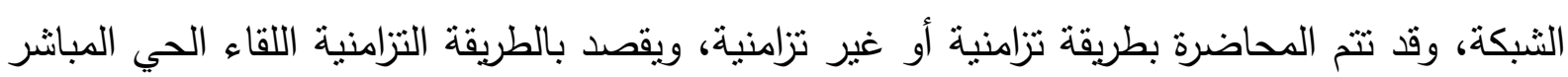
بين المعلم والمتعلم عبر الثبكة في نفس الوقت، ويمكن أن تكون بشكل غير تزامني، حيث يتم نئم نشرها

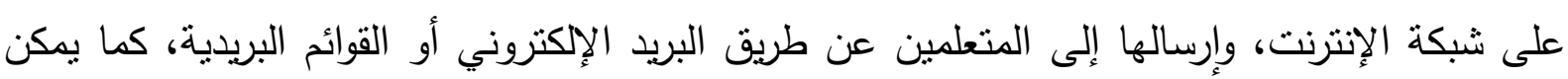

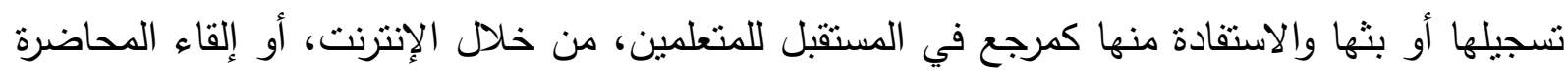

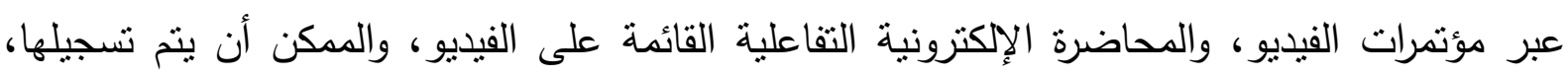
وبعد ذلك تعرض على شبكة الإنترنت، حيث تكون متاحة للطلاب في أي وقت ومن أي مكان. وقد عرف نبيل عزمي (327،2008) المحاضرة الإكترونية بأنها طريقة لتقديم الحقائق

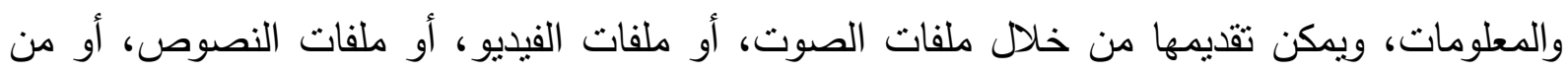

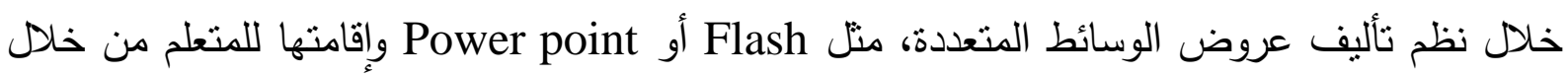

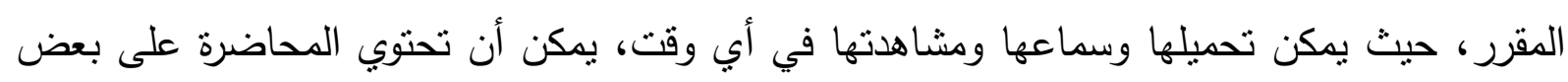
الروابط المرتبطة بموضوع الدرس. 
ويعتمد الدحاضر في الجامعات الليبية على المحاضرات التقليدية في عرض المحتوى التعليمي

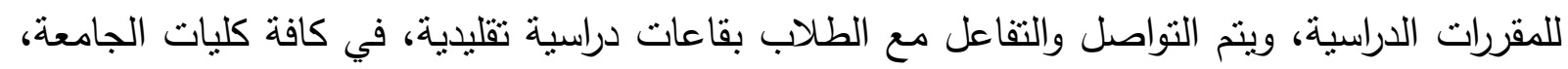

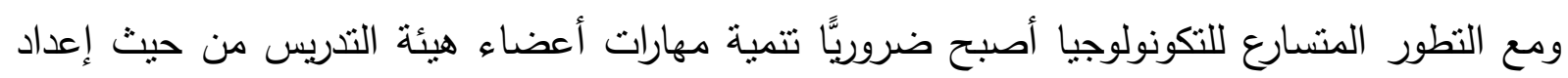

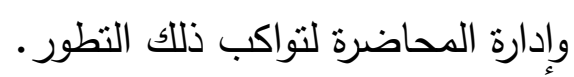

ويعد التعلم من بعد هو أحد طرق التعليم الحديثة نسبيًا ويعتمد مفهومة الاساسي على أتمام العملية

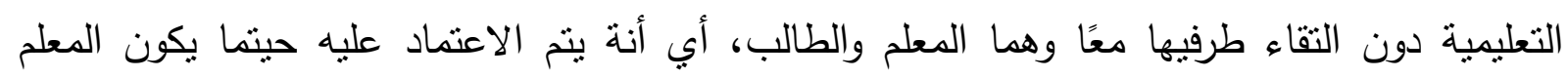

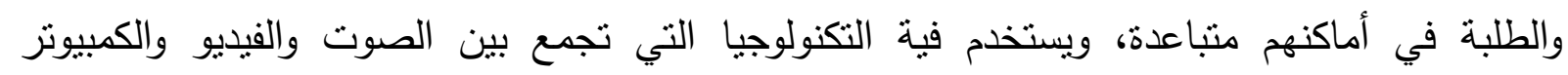

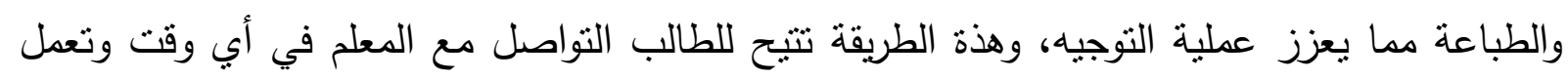

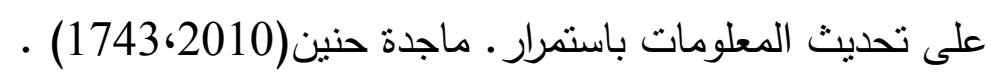

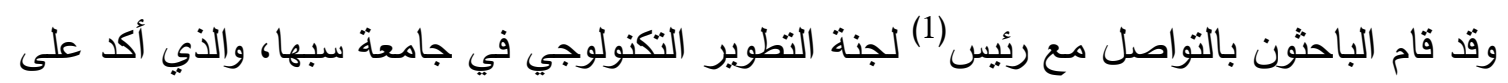

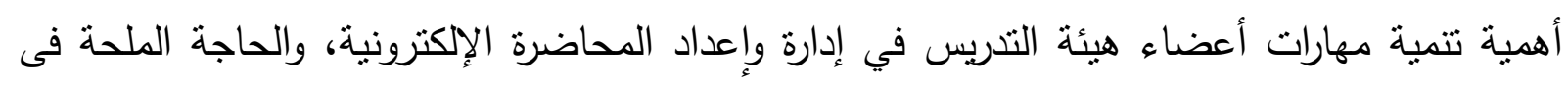

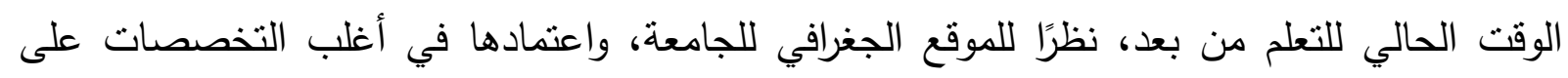
الأساتدة الزائرين، مما يجعل هناك صعوبة في سفرهم وتنقلهم وإقامتهم.

مشكلة البحث:

تخضع المحاضرات كأب مستحدَث تكنولوجي إلى التطوير المستمر، بما يتماثى مع التقدم

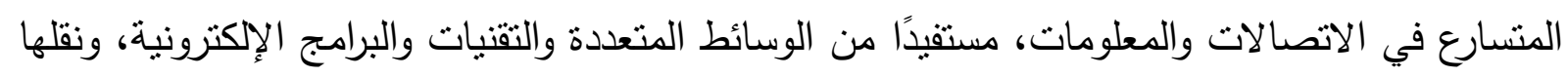

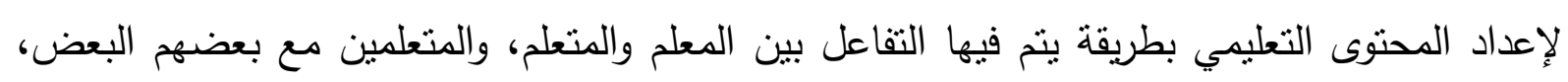

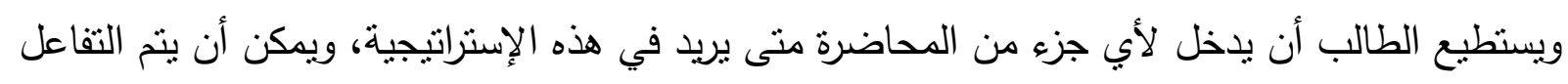
بين المعلم والمتعلم بثكل مباشر من خلال البريد الإلكتروني، والقوائم البريدية، وإرسال الأسئلة الإنة

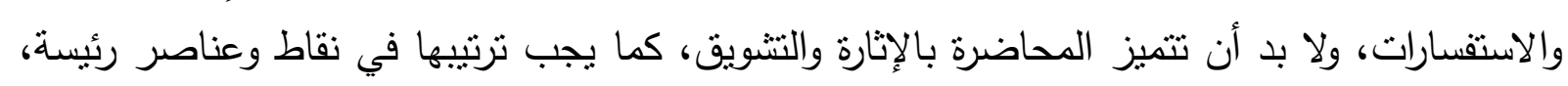

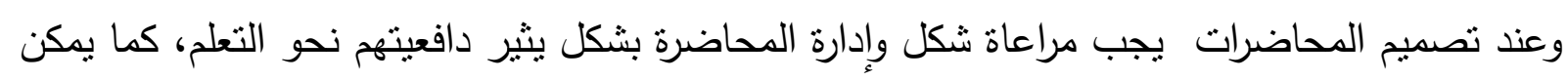

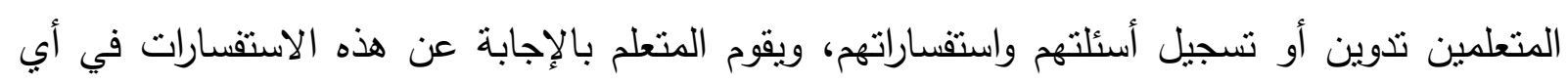

$$
\text { وقت (جمال مصطفى عبد الرحمن، 2010). }
$$

ومن خلال ما قام به الباحثون من دراسة استكثنافية، تمثلت في استبانة إلكترونية، ثم إعدادها باستخدام Google Drive وإرسالها على Messenger، والتي هدفت للتعرف على دلى الواقع الحالي 
لتوظيف تكنولوجيا التعليم بجامعة سبها، وكذلك الاحتباجات التدريبية لأعضاء هيئة التدريس في جامعة

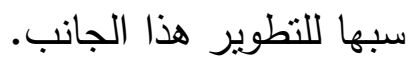

تم تقسيم الاستبانة إلى ثلاثة أقسام رئيسة، تتضمن: - القسم الأول: بيانات عامة عن عضو هيئة التشريس.

- - القسم الثاني: الواقع الحالي لتوظيف تكنولوجيا التعليم بجامعة سبها.

- القسم الثالث: الاحتباجات التدريبية لأعضاء هيئة التدريس في جامعة سبها.

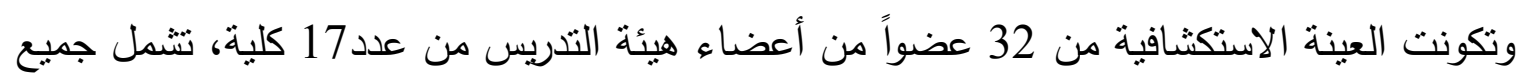

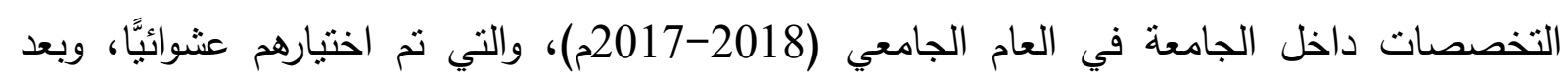
تحليل نتائج تطبيق الاستبانة الإلكترونية تبين الاتي:

ل الواقع الحالي لتوظيف تكنولوجيا التعليم بجامعة سبها: • اتفق نسبة (78.5\%) لا يعرفون ما هي تكنولوجيا التعليم.

• اتفق نسبة (62.2\%) لا يستخدمون الباوربوينت (power point) في عرض المحاضرات.

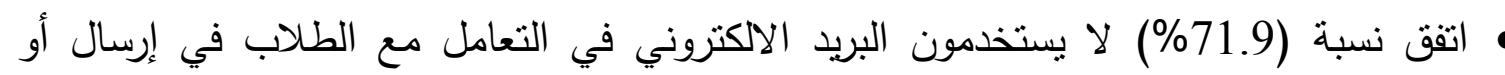

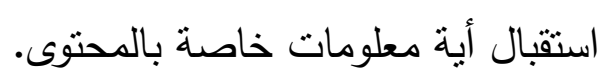

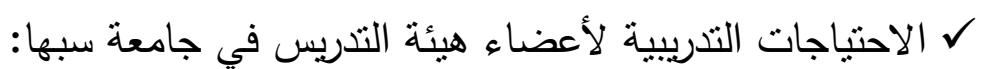

• اتفق نسبة (96.9\%): على أنه توجد لايهم رغبة في استخدام التكنولوجيا في العملية التعليمية.

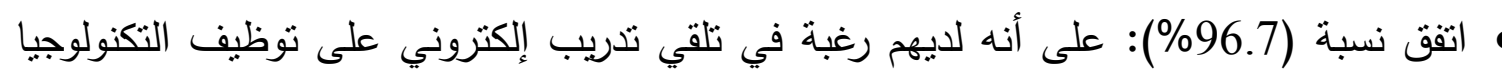
في العملية التعليمية.

• اتفق نسبة (78.1\%): لديهم الرغبة في التعرف على الدحاضرات الإلكترونية.

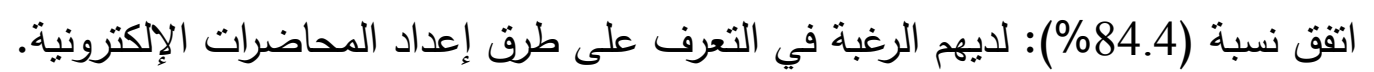

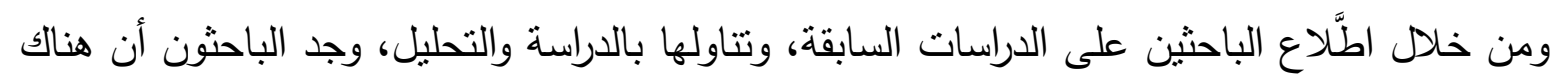
ندرة في الدراسات والبحوث، التي تهتم بأساليب التدريس القائمة على توظيف التكنولوجيا في العملية التئه

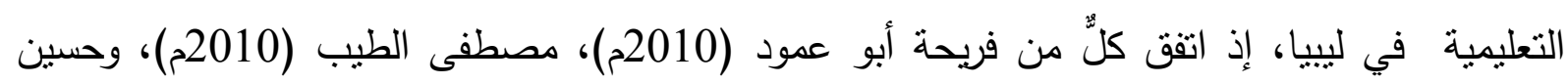

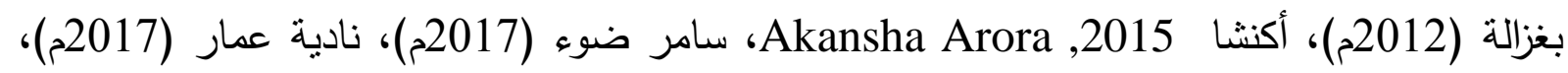
على إعادة النظر في أساليب التدريس القائمة حاليًا، وتوظيف تكنولوجية المعلومات في العملية التعليمية، وعدم وجود مهارات لإعداد وإدارة المحاضرة الإككترونية من بعد لدى أعضاء هيئة التدريس في جامعة 
سبها الليبية. ويمكن تحديد مشكلة البحث في عدم وجود مهارات محددة لنظوير المحاضرات الإكترونية، وإدارتها من بعد، لاى أعضاء هيئة التدريس في جامعة سبها اللبيية. أسئلة البحث:

يمكن معالجة مشكلة البحث من خلال الإجابة عن السؤال التالى:

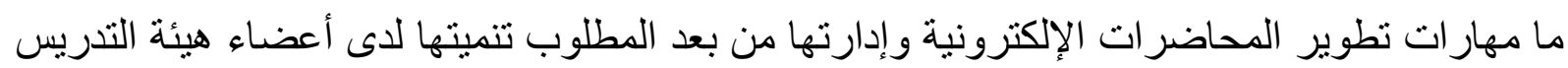

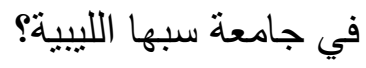

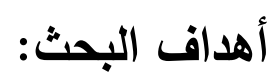
يهدف البحث الحالي إلى تحديد قائمة بمهارات تطوير الدحاضرات الإككترونية وإدارتها من بعد، الواجب توفرها لاى أعضاء هيئة التدريس في جامعة سبها الليبية. أهمية البحث: البه:

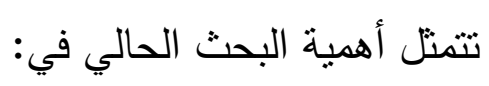

توجيه نظر المتمين الي ضرورة تحسين أداء أعضاء هيئة التدريس بجامعة سبها وبقية الجامعات الليبية. تقديم قائمة بمهارات تطوير المحاضرات الإلكترونية، وإدارتها من بعد، والتي يمكن الرجوع إليها عند تتمية مهارات أعضاء هيئة التدريس في جامعة سبها الليبية

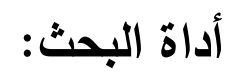
أعد الباحثون استبيانه لاستطلاع آراء الخبراء وأعضاء هيئة التدريس والمتخصصين في مجال

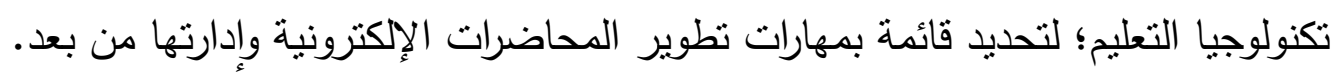

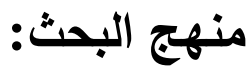

اعتمد البحث على المنهج الوصفي التحليلي في اثتقاق قائمة مهارات تطوير المحاضرات

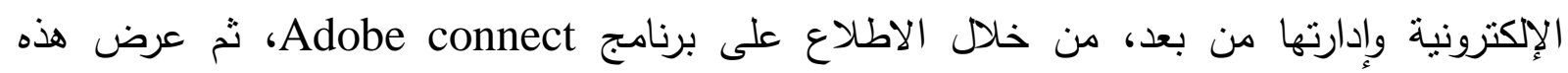
المهارات على عينة من الأساتذة والخبراء فى مجال تكنولوجيا التعليم لإجازتها. حدود البحث: - اقتصر البحث الحالي على مجموعة من الأساتذة والخبراء في مجال تكنولوجيا التعليم. - - المحاضرات الالكترونية من بعد عبر الويب. 
Adobe المهارات اللازمة لنطوير المحاضرات الإلكترونية، وإدارتها من بعد، باستخدام برنامج - connect إجراءات البحث:

سار البحث وفق الخطوات الإجرائية التالية:

1- الاطلاع على الأدبيات السابقة الخاصة بموضوع البحث، وكذاللك برنامج Adobe connect،

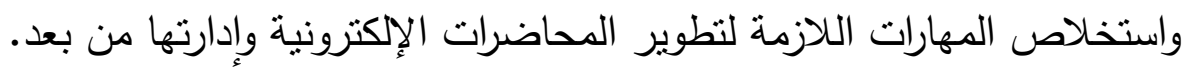

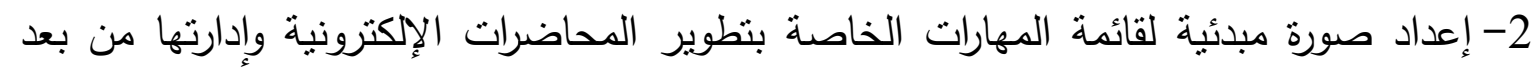

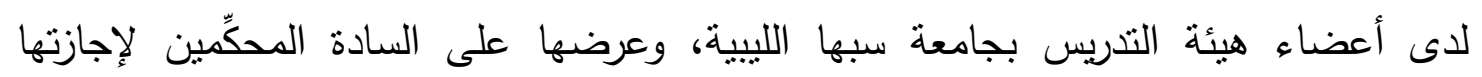
ووضعها في صورتها النهائية. 3- إعداد أداة البحث، والتي تمنلث في استبانة تتضمن قائمة مبئية بمهارات نطوير المحاضرات

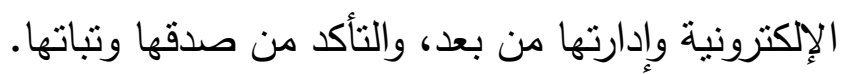
4- اختيار عينة البحث. 5- تطبيق أداة البحث ومعالجتها إحصائيًا.

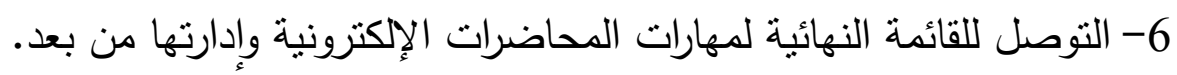
مصطلحات البحث: تضمن البحث المصطلحات التالية: :skill المهارة

هى القدرة على القيام بأي عمل من الأعمال بدرجة عالية من الدقة، والسرعة، والاقتصاد في الوقت والجهد المبذول مصطفى عبد السميع (2012م).

ويعرف الباحثون المهارة إجرائيًا في هذاالبحث على إنها قدرة أعضاء هيئة التدريس على الكي إعداد المحاضرة الإلكترونية وإدارتها من بعد، على أكمل وجها، ووفقًا للمعايير التربوية

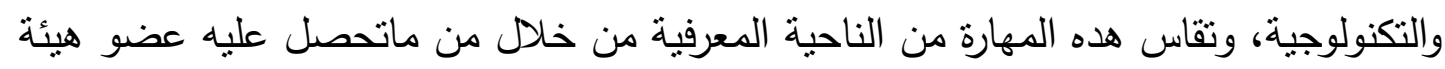

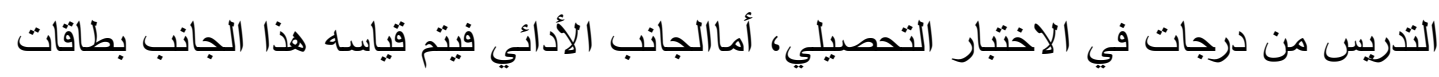
الملاحظة للاداء العملي لعضو هيئة التدريس. 2- المحاضرة الإكترونية Electronic-Lecture: 


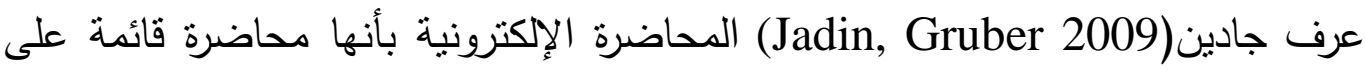

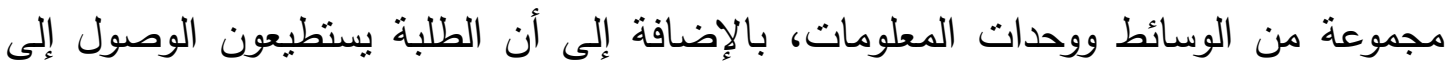

$$
\text { المحاضرة ومصادر التعلم بسهولة. }
$$

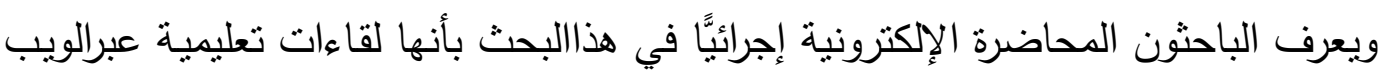
لتتمية مهارات إعداد وإدارة المحاضرات الإلكترونية؛ لأعضاء هيئة التنريس.

\section{3- Distance learning التعلم من بعد}

يعرف محمد خميس (2009،83) التعلم من بعد على أنة نظام تعليمي رسمي، يقوم بعمليات تعليم وتعلم، على أساس الفصل شبة الدائم بين المعلم والمتعلمين، وبين المتعلمين بعلين بعضهم البعض، يقدم من خلال مؤسسة تعليمية رسمية، تقوم بعمليات تخطيط المواد التعليمية

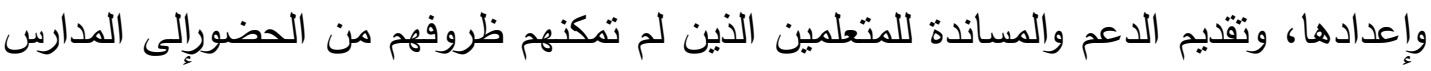
والجامعات، ويعتمد على توصيل المحتوى والمواد التعليمية في شكل رزم package وحقائق التدريبات العملية kite باستخدام وسائط تكنولوجية، ويقوم المتعلمين بدراستها بشكل مستقل، بمساعدة التعليمات التي تقدم من خلال هذه المواد، تحت إثراف المعلم وتوجيهه، الذي يتفاعل معهم عن بعد، باستخدام وسائط اتصال تكنولوحيا. ويعرف الباحثون النعلم من بعد إجرائيًا في هذالبحث بانه قدرة أعضاء هيئة التدريس

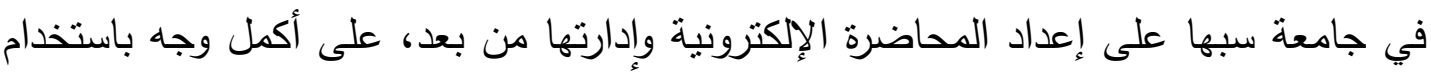
برنامجAdobe connect

أعضاء هيئة التدريس بجامعة سبها إجرائيًا: هم جميع أعضاء هيئة التدريس من حملة

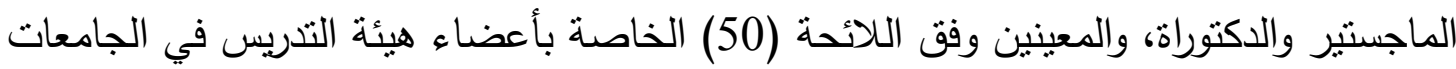
الليبية، والصادرة من وزارة التعليم العالي في ليييا. 


\section{الإطار النظري للبحث}

تتاول الباحثون في هذا الجزء مفهوم المحاضرة الإكترونية، وخصائصها، وأهميتها، ومميزاتها،

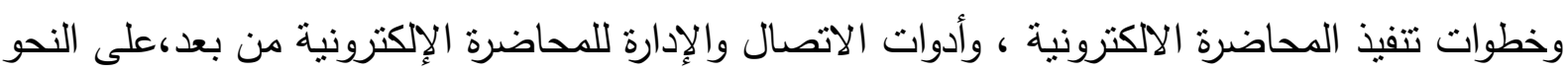
النالي:

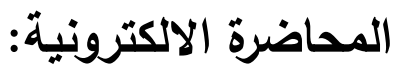

تعد المحاضرة الإلكترونية أسلوبًا من أساليب التعليم الحديثة، والتي توفر للطلاب المعرفة والمعلومات بسرعة، وتمكنه من التفاعل مع زملائه ومعلميه لمناقثنة المحتوى التعليمي. وتقدم للمتعلمين سواء في مجال التعليم أو التدريب وفي كافة المستويات الدراسية - المناخ المناسب للتعلم، وذللك بالاستفادة

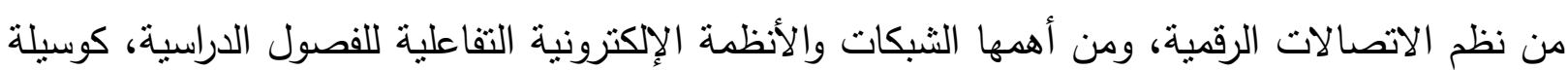
أساسية للتواصل بين المعلم والمتعلم (Sharma, Guota 2012).

وعرف الغريب زاهر (2009م، 74) المحاضرة الإككترونية بأنها الموضوعات التي يتم مناقتنها إلكترونيًا عبر الإنترنت، ويقوم عضو هيئة التنريس في التعلم الإلكتروني باختيار الموضوعات المناسبة لسن الطالب والمرحلة التعليمية، من حيث الانتهى الطلاب في المرحلة السابقة. ويمكن أن بنقل المعلم الدرس عن طريق إلقاء المحاضرات عبر الثبكة، وقد تتم الدحاضرة بطريقة

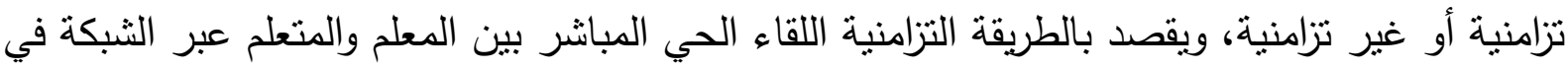
نفس الوقت، ويمكن أن تكون بشكل غير نتامني، فيمكن أن تكون منقولة من خلال نشرها على شبكة

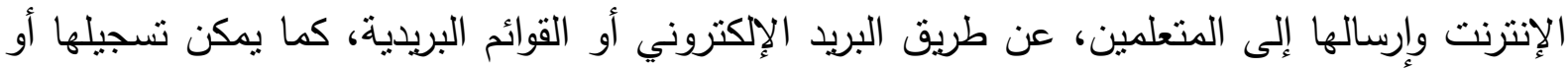

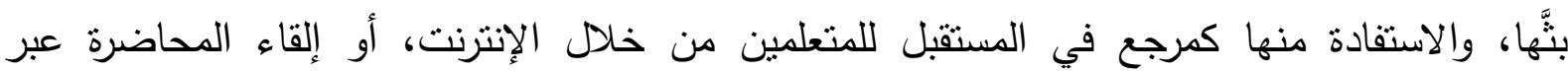

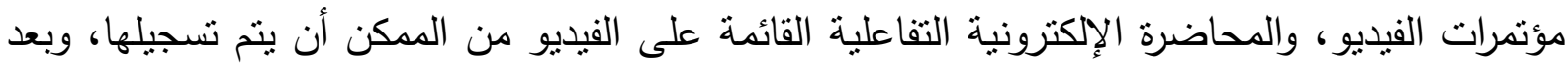
ذلك تعرض على شبكة الإنترنت، حيث تكون متاحة للطلاب في أي وقت ومن أي مكان. أيضًا من الممكن أن يقسم المحتوى على أجزاء صغيرة وتوضع داخل جداول، ثم ترفع على شبكة

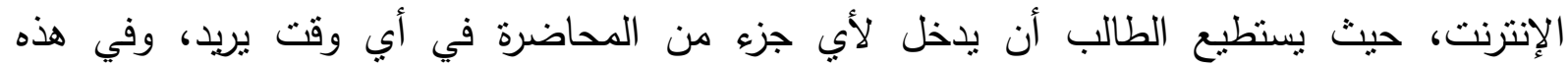

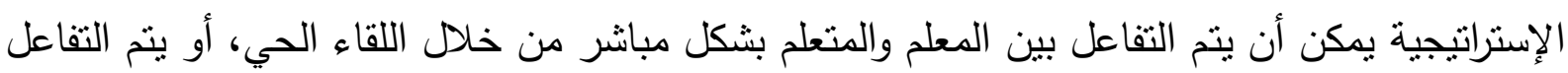

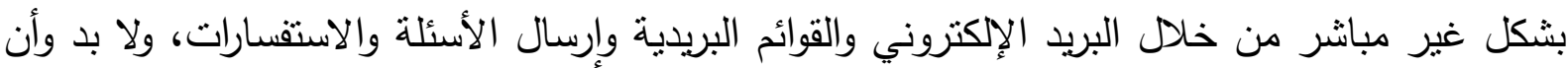
تتميز المحاضرة بالإثارة والتشويق، كما يجب ترتيبها في نقاط وعناصر رئيسة، ويجب عند تصميم

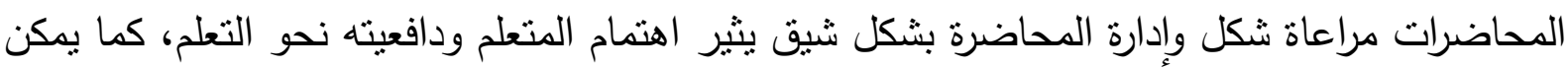


للمتعلمين تدوين أو تسجيل أسئلتهم واستفساراتهم، ويقوم المعلم بالإجابة عن هذه الاستفسارات في وقت لاحق.

\section{خصائص المحاضرة الإكترونية:}

تهدف المحاضرة الإلكترونية إلى مساعدة الراغبين في التعليم إلى الانخراط في الدراسة في أي

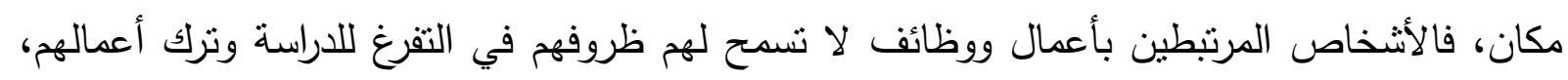

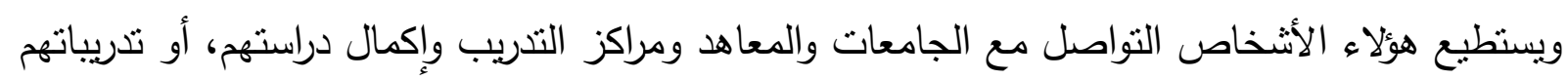
من خلا هدا الأسلوب من التعلم.

وذكر جمال الثرقاوي (2010)، وأكانشا (Akansha Arora,2015) أن المحاضرة الإكترونية

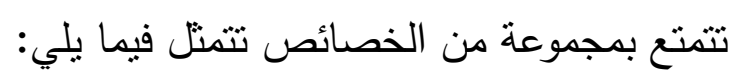

- الإتاحة: ويقصد بها سهولة الوصول إلى محتوى المحاضرة الإكترونية ومشاهدته في أى وقت

$$
\text { وأي مكان عبر الويب. }
$$

- المرونة: ويقصد بها إمكانية تسجيل المعلم للمحتوى، وبثه عبر الويب فيما يسمى بتدفق الوسائط،

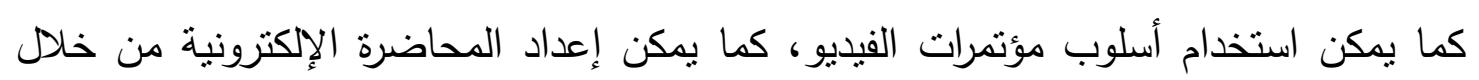

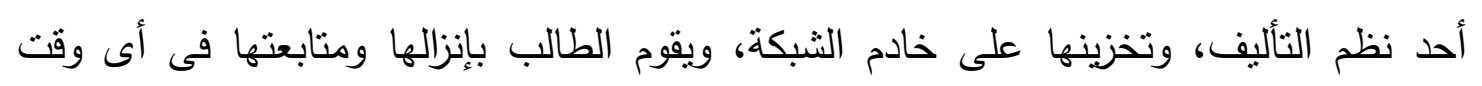

$$
\text { يناسبه. }
$$

- يمكن للمحاضر أن يحدد من يرغبون في الحضور معه أو يشتركون في هذا المقرر، كما يمكن

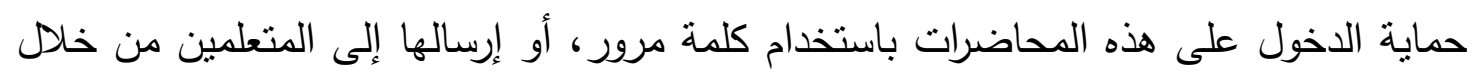

$$
\text { البريد الإكتروني. }
$$

- الفردية: ويقصد بها مراعاة المحاضرة الإلكترونية لخصائص المتعلمين، والفروق الفردية بينهم،

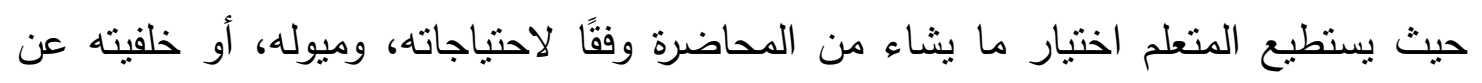

$$
\text { الموضوع. }
$$

- التكاملية: ويقصد بها التكامل بين الوسائط المتعددة المستخدمة فى تقديم المحتوى التعليمي. - التفاعلية: ويقصد بها إمكانية التفاعل بين المعلم والمتعلم من جهة، وبين المتعلم ومصادر التعلم

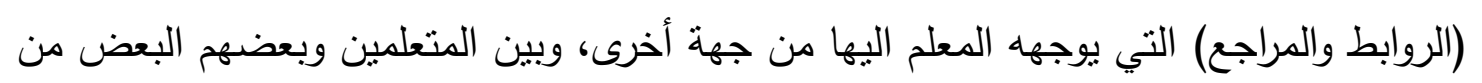
جهة أخرى. - الوسائط المتعددة: ويقصد بها إحتواء المحاضرة الإكترونية على وسائط متعددة، منل الرسوم المتحركة والصور ولقطات الفيديو ومقاطع صوتية ونصوص. 
ويرى الباحثّن انه يمكن الاستفادة من تطوير المحاضرات الالكترونية لاى أعضاء هيئة التدريس،

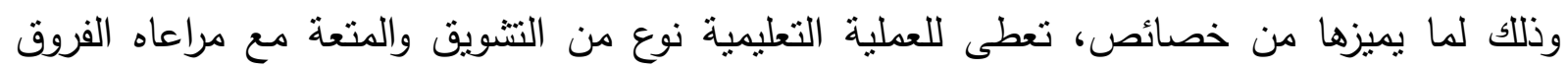

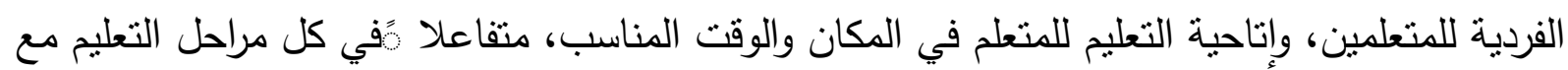
زملائة ومعلمية.

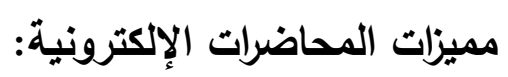

يثير محمد راضي، أيمن أبو غازي (2013، 316) وكانتوني (Cantoni, V.2004 )p334 ) إلى مجموعة من المميزات، التي تتميز بها المحاضرة الإلكترونية، وتثنمل: - - - إمكانية الوصول إلى المتعلمين بشكل فردي. - - مخفيض تكاليف التعليم. - - - إعطاء المتعلم الفرصة في اختيار ما يريد أن يدرسه في الوقت الذي يريده. - - التقييم الذاتي؛ حيث تتاح للمتعلم حل التمارين ومعرفة مستواه في الحال.

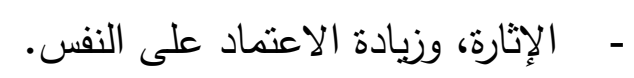
- حل بعض المشكلات التربوية، منل تزايد أعداد الطلاب وعدم استيعابهه في الفصل التقليدي.

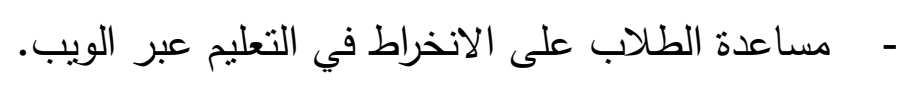

- - تتيح المحاضرة الاكترونية للمعلمين التفاعل مع الطلاب من خلال البريد الإلكتروني والدردشة. - - سهولة الوصول الى مجموعة واسعة من الروابط دات الصلة بالمحتوى المقدم.

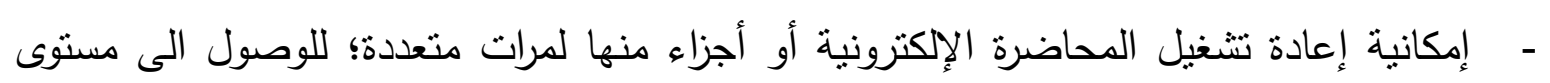

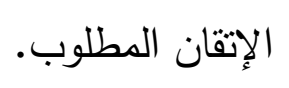
- سهولة ترتيب وتحديث المحاضرة الإلكترونية، والتحكم فيها. ويرى الباحثون أن المحاضرات الالكترونية تتميز بالعديد من المميزات الني جعلت منه التهن أمراً

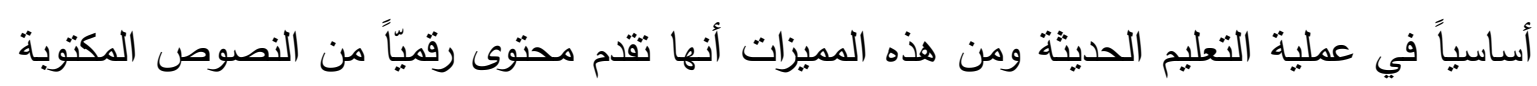

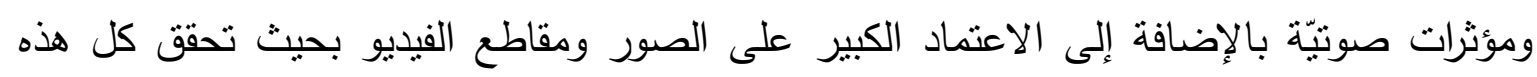

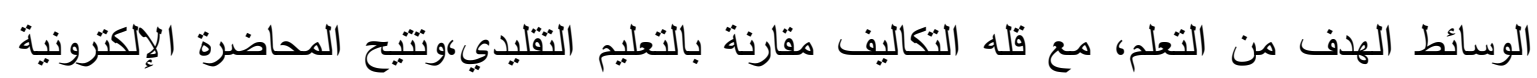

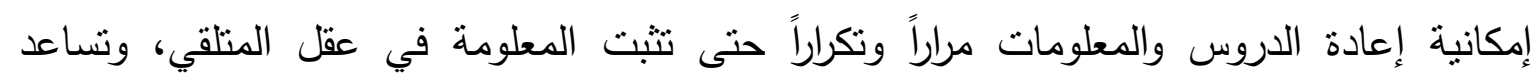

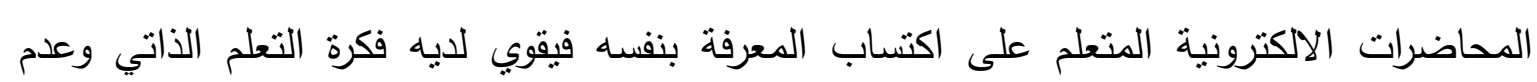
الاعتماد على غيره في ذلك.

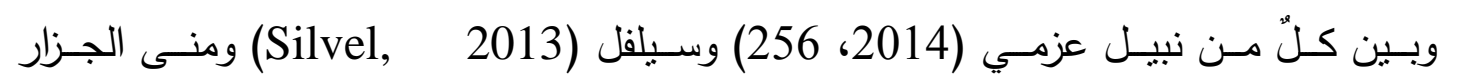
(2014، 177) أن الخطوات اللازمة لتنفيذ المحاضرة الإلكترونية الجيدة كالتالي: 
1- التخطيط للموضوع: حيث يقوم عضو هيئة التدريس بالإعداد الجيد للمادة التعليمية، في مخطط

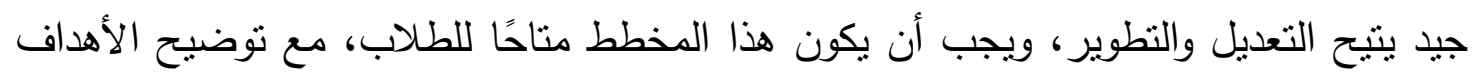
التعليمية الخاصة بالمحاضرة في هذا المخطط. 2- استخدام مُدخل بسيط: وذلك بوضع مخطط يجبر المتعلمين بما سوف يتعلموه، وما هو مطلوب فئل منهم من تكليفات ومسئوليات.

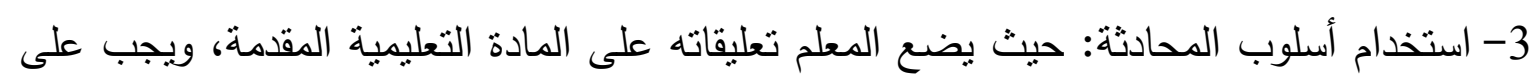
المعلم تحديد خصائص طلابه، والاستعانة بالوسائط البصرية المتتوعة.

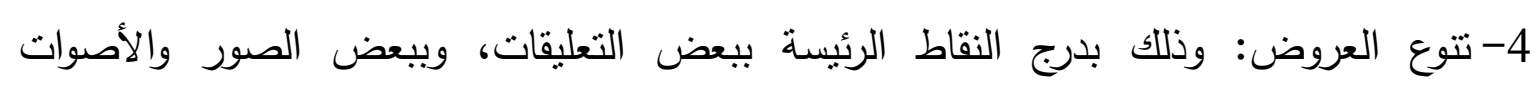
والتعليقات.

5- إظهار الممارسة: لابد من إظهار حماس المعلم تجاه المادة التعليمية؛ ليكتب الطلاب الطاقة

$$
\text { وتنتخيصهم على الاستماع والمتابعة. }
$$

6- تطور المحتوى: وذلك من خلال إظهار التشويق على المحتوى، وذلك عن طريق إنهاء المحاضرة

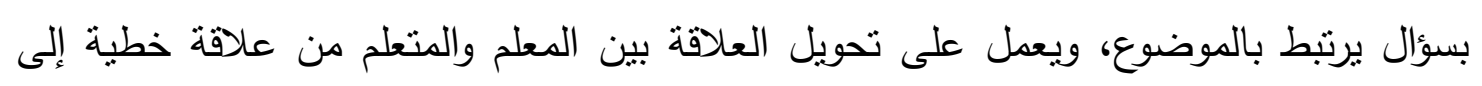

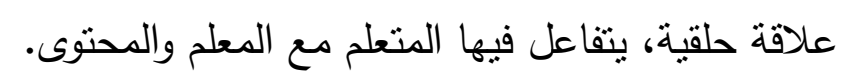

\section{أدوات التقاعل وأنماط تقديم المحتوى في المحاضرة الإكترونية:}

يعد التفاعل العمود الفقري في التعليم الالكتروني، ومن خلال التفاعل يستطيع المتعلم أن ينغس

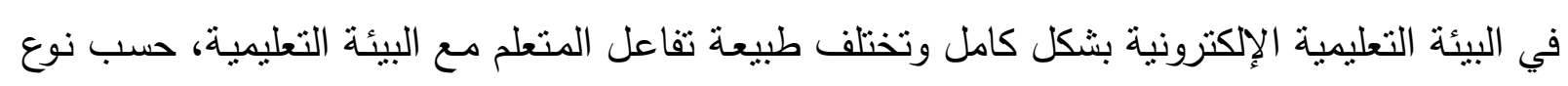
التفاعل، كما يعتمد التفاعل بشكل كبير على التقنيات والأدوات، التي توفرها بيئة التعلم (محمد خميس،

ويتم التعلم في المحاضرة الإكترونية عبر مجموعة من أدوات التفاعل المتزامنة وغير المتزامنة،

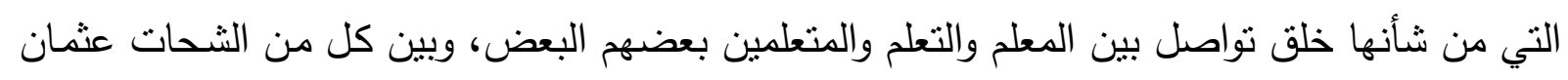

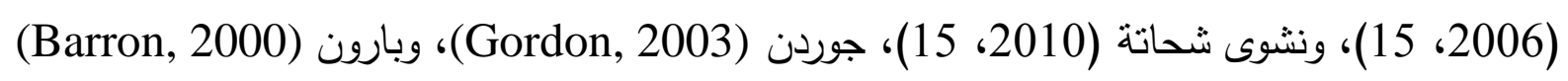
أن عرض المحتوى عبر الثبكات يتم وفق نمطين: - النمط التزامني: وتتم العملية التعليمية في هذه الحالة بصورة مباشرة، ويتم التفاعل مباشر بين

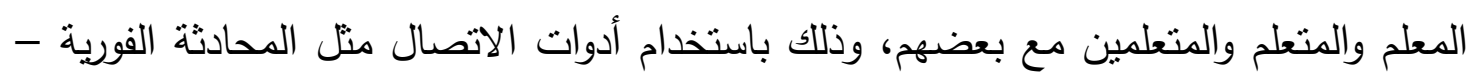
المؤتمرات السمعية - مؤتمرات الفيديو - مجموعات النقاش. - النمط غير التزامني: وتتم العملية التعليمية في هده الحالة بصورة غير مباشرة، ويتم استخدام

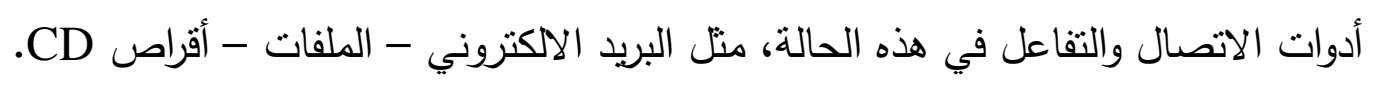




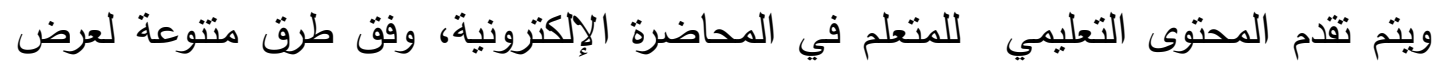

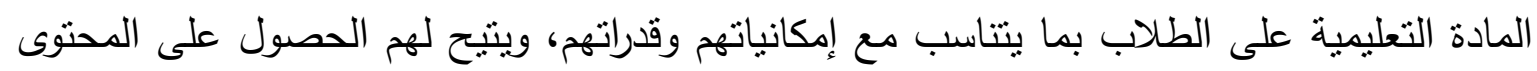

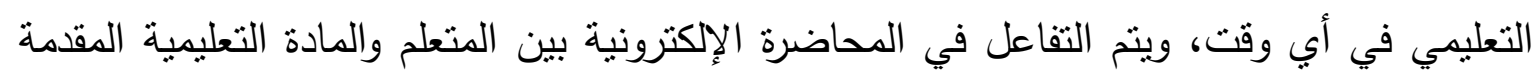

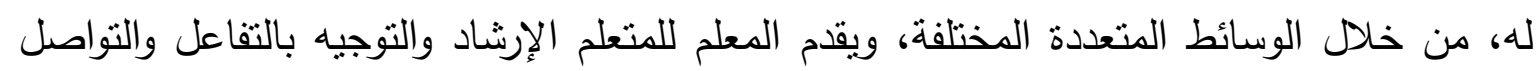

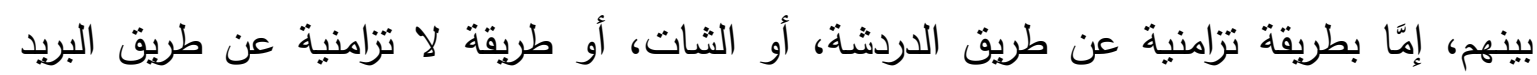

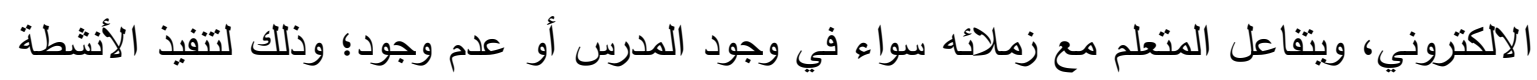

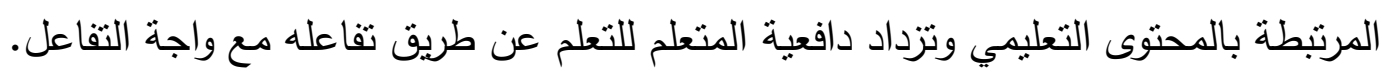
وبينت دراسة جو وكيم وروبن (Guo, Kim, \& Rubin, 2014) أن هناك ثلاثه أنماط لتقديم

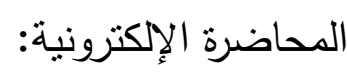
- البث المباشر للمحاضرة: ويعني التقاط المحاضرة التقليدية الحية، وبثها بشكل مباشر على الطلاب عبر شبكة الانترنت، حيث يتم وضع الكاميرا في المحاضرة، ويقوم المحاضر بإعطاء محاضرته التقليدية للطلاب، ويتم تسجيل المحاضرة، ويأخذ هدا النمط الثكل التقليدي للمحاضرة.

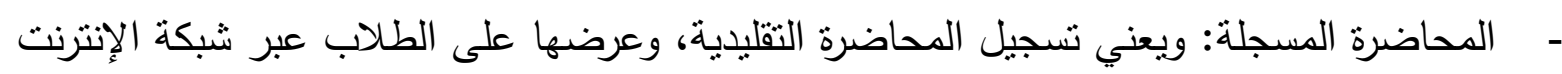
بشكل متزامن، وهذا النمط أيضًا يشبه الثكل التقليدي للمحاضرة، إلا أنه يسمح للمتعلم بإعادة تشغيل المحاضرة أكثر من مرة. - المحاضرة على الثبكة: وتعني أن المحاضر بسنطيع أن يقدم مادته العلمية بالصوت والصورة

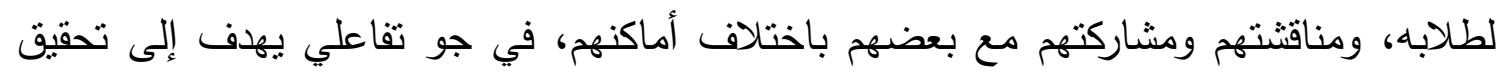

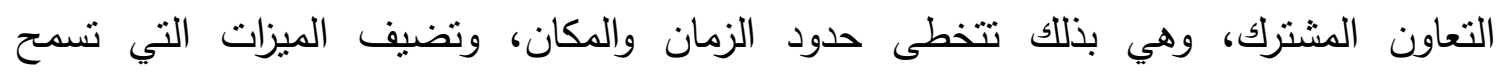

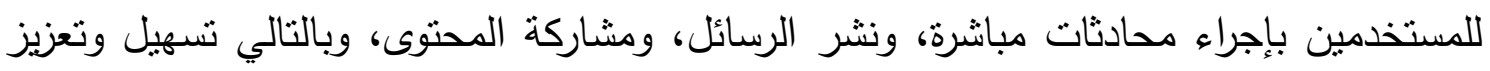
التفاعل بين المتعلمين.

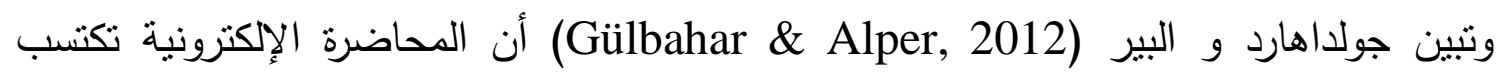

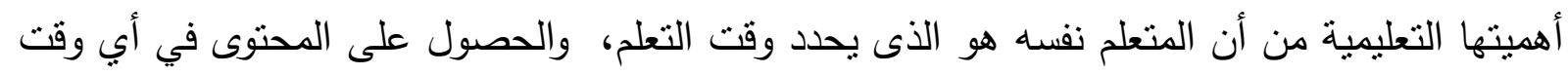

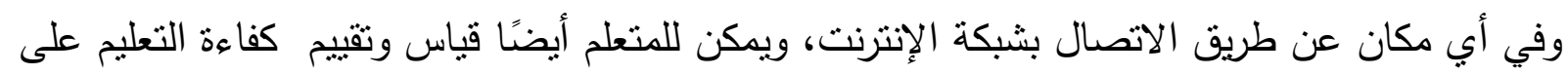

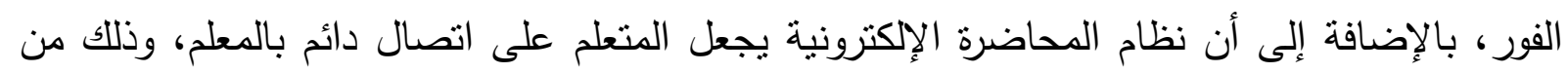

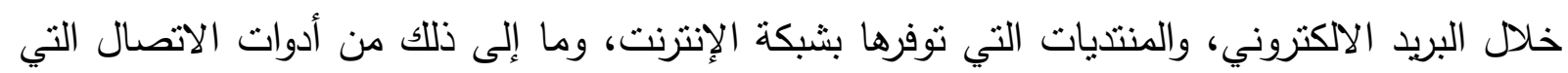
تمكن المتعلمين من المشاركة في إحداث التعلم الفعال. 


\section{إنتاج وإدارة المحاضرة الاكترونية:}

يمكن إعداد المحاضرة الاكترونية وإدارتها وإتاحتها للطلاب عبر نظم إدارة التعلم الإلكتروني

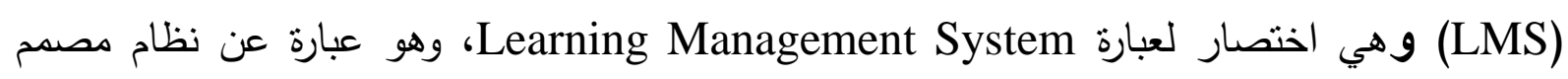
خصيصاً لإدارة المقررات الإككترونية (Ninoriya et al., 2011). نظام (LMS) صمم للمساعدة في إدارة ومتابعة وتقييم التدريب والتعليم المستمروجميع أنشطة التعلم في

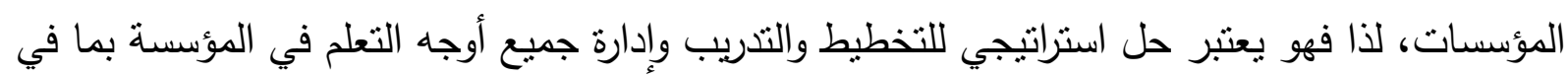

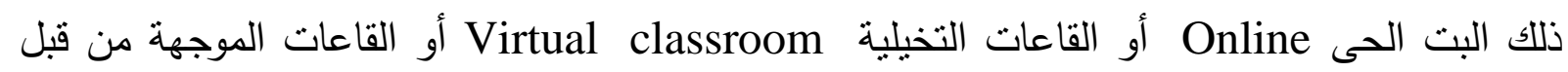
الدربين (أماني عوض، الثحات عثمان، 2007، 250).

ويوجد العديد من أنظمة وبرامج إعداد وإدارة المحاضرة الالكترونية من بعد ويمكن إختبار الافضل

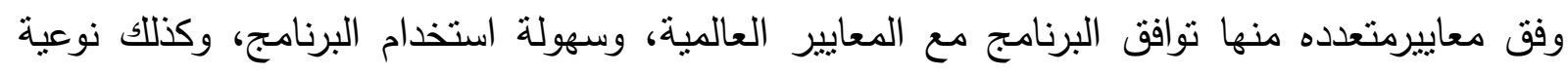

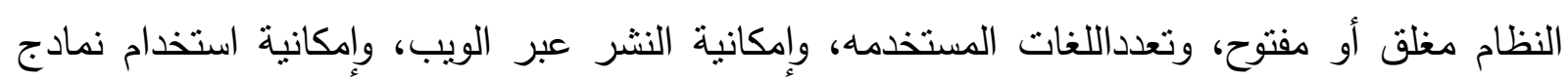

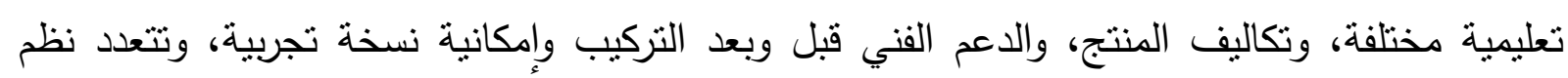
وبرامج إدارة المحاضرات الالكترونية سواءكانت مفتوحة او مغلقة المصدر ومنها: نظامب(https:// lms.kku.edu.sa) Moodle)، نظام

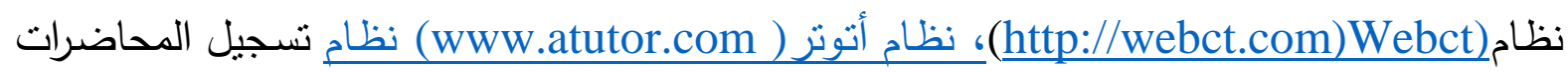
( ) برنامج ووردبريس (http://tegrity.kku.edu.sa) (Tegrity)

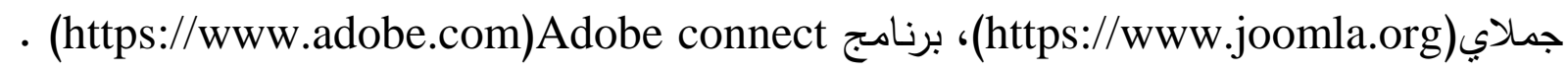
وقد إختار الباحثون برنامج الادوبي كونكت Adobe connect الإصدار 9.3، وفيما يلي عرض لهذا البرنامج:

\section{برنامج Adobe connect}

تعد شركة أدبي Adobe connect من الثركات الرائدة في مجال البرمجيات، أسسها رتثارلز

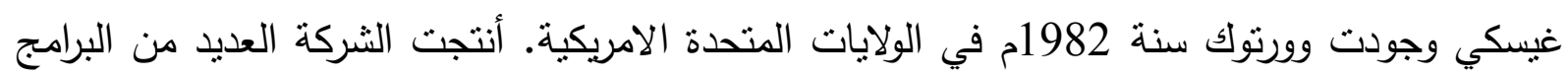

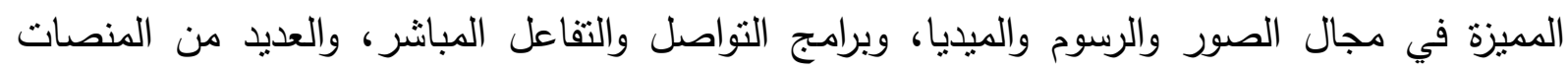

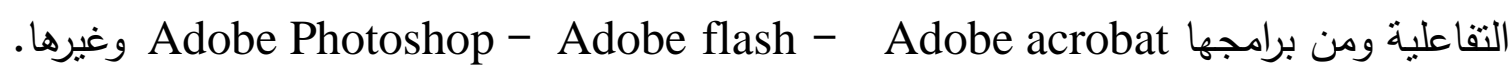
ويمكن تعريف برنامج الأدبي كونكت بأنه برنامج إلكتروني تعليمي، ينتح للطالب التفاعل والمشاركة

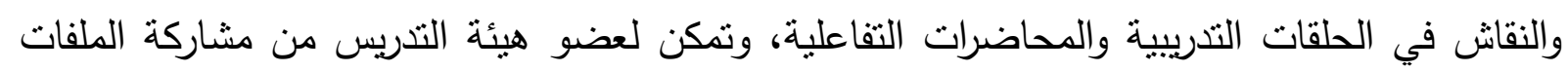

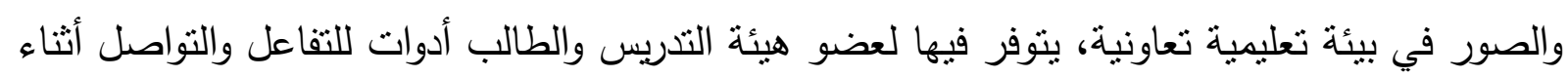


المحاضرة، ويهدف هذه البرنامج إلى تخطي حاجز الزمان والمكان، والحصول على عدد أكبر من

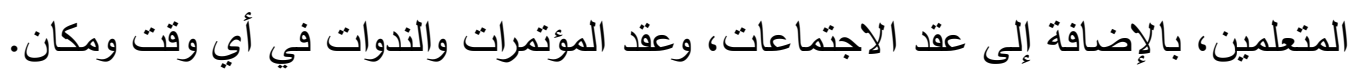

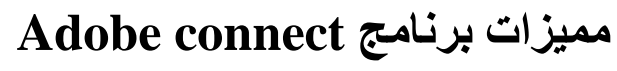

$$
\begin{aligned}
& \text { - - المرونة في الاستخدام. } \\
& \text { - - تخطي حدود الزمان والمكان. }
\end{aligned}
$$

- - إكانية استخدام برامج أجهزة الحاسب المكتبي والمحمولة، وكذللك الأجهزة الذكية. - - تعدد الخيارات داخل المنصة التعليمية، والتي تتيح لعضو هيئة التنريس والطالب استخدامها.

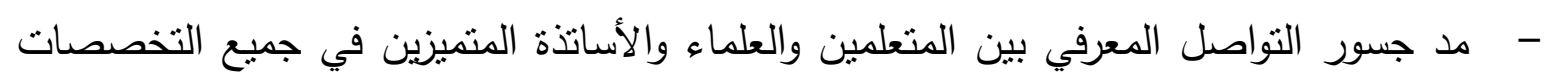

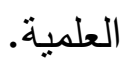
- إمكانية طرح القضايا العلمية والاستفسار من عدة أمور بكل سهولة، والحصول على نصائح وتغدية راجعة فورية. - - يوفر البرنامج استخدام الصوت والصورة والمحادثة والنص، وكذلك مشاركة الملفات وشاشات الكمبيوتز بين عضو هيئة التدريس والطالب.

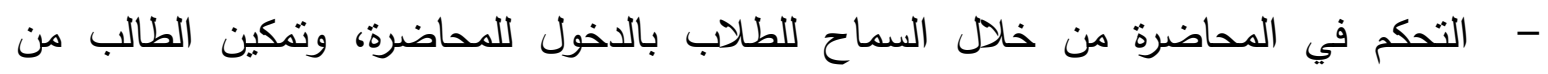
المحادثة من عدمها، وكذلك يمكن للطالب طلب المداخلة أتتاء المحاضرة. - ميكن تشجيل المحاضرات، وعرضها لاحقًا. :Adobe connect مكونات برنامجن يتكون برنامج Adobe connect من الصفحات التالية: 1-الصفحة الرئيسة، وتحتوي على: المحاضرات المسجلة والجاهزة، القائمة الرئيسة، إعداد محاضرة

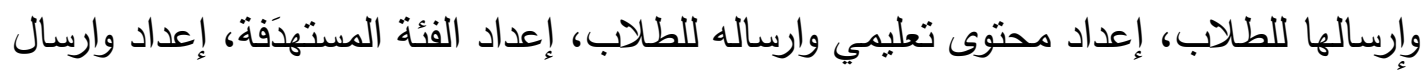
تعليمات للطلاب عن المحاضرة.

2-صفحة الاخول، وتحتوي على: اسم المستخدم Username، كلمة المرور •

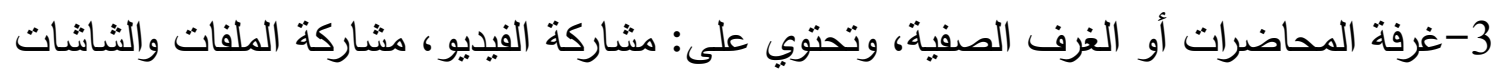
والمستندات، لوحة الإعلانات، السبورة التعليمية، لوحة الثات. 


\section{إجراءات البحث والدراسة الميدانية:}

تتاول الباحثون جميع الاجراءات والخطوات الازمة لانجاز هذا البحث: إعداد استبانة لتحديد قائمة بمهارات تطوير المحاضرات الإكترونية وادراتها من بعد والمطلوب تنميتها لاى أعضاء هيئة التدريس بجامعة سبها الليبية. 1. تحديد الهوف من قائمة المهارات: تمثل الهدف من إعداد القائمة فى التوصل إلى قائمة بمهارات تطوير الححاضرات الإكترونية وإدراتها من بعد والمطلوب تتميتها لاى أعضاء هيئة التندريس بجامعة الهنة سبها الليبية.

2. إعداد وبناء قائمة المهارات: تم بناء قائمة المهارات من خلال دراسة وتحليل الدراسات والأدبيات

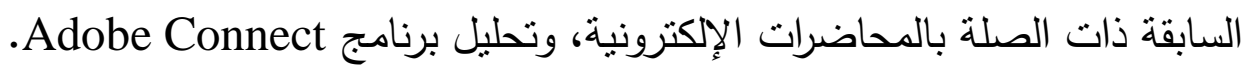
3. إعداد الصورة المبئية لقائمة المهارات: تم صياغة المهارات التى تم التوصل إليها من المصادر

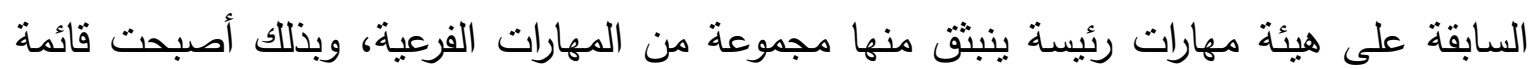
المهارات فى صورتها المبئية تتكون من (3) مهارة رئيسة، (22) مهارة فرعية.

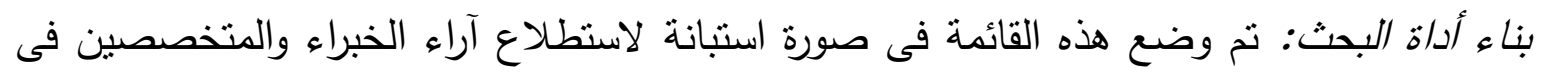

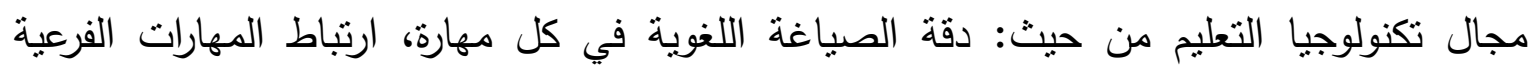

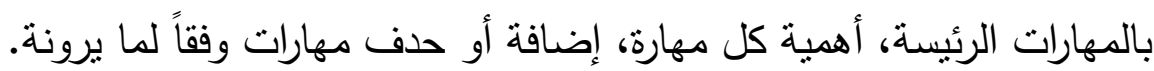
4. اختبار عينة البحث: مجموعة من الخبراء والمتخصصين فى مجال تكنولوجيا التعليه. 5. تطبيق أداة البحث: • التحقق من صدق قائمة الهارات: تم عرض قائمة مهارات نطوير المحاضرات الإلكترونية وإدراتها من

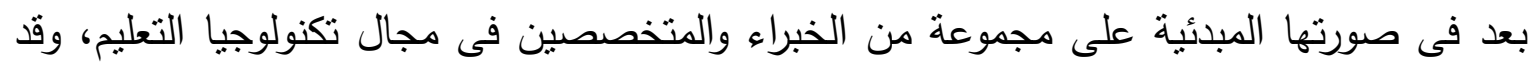
استغرق تطبيق هذه الاستبانة حوالى ثلاثة أسابيع.

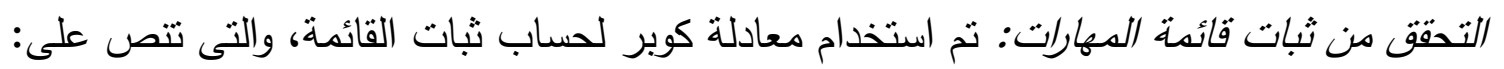

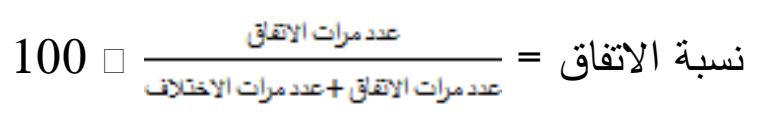

حيث يتم الإبقاء على المهارات التى نأخذ نسبة اتفاق أكثر من 85\% فأكثر ، واستبعاد المهارات التى

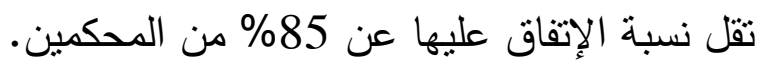
المعالجة الإحصائية: تم معالجة البيانات إحصائيًا من خلال حساب نسبة الاتفاق باستخدام معادلة كوبر • 


\section{نتائج البحث وتفسيرها:}

الإجابة عن السؤال البحثي والذى ينص على " ما مهارات تطوير المحاضرات الإلكترونية وإدارتها من بعد

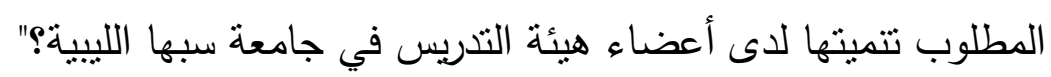
قام الباحثون بإعداد إستبانة لتحديد قائمة مهارات تطوير المحاضرات الإلكترونية وإدارتها من بعد

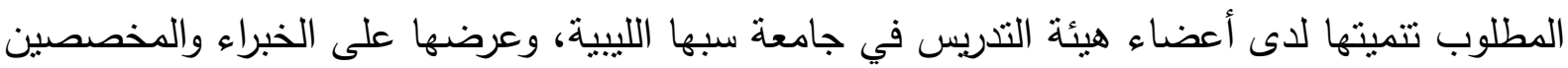

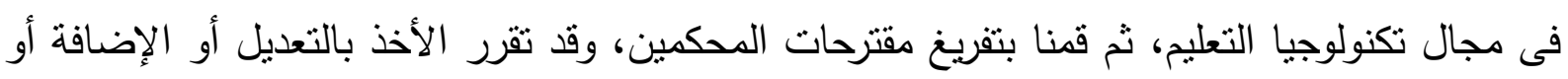
الحذف إذا اتفق عليه أكثر من محكم، كما تم حساب نسبة الاتفاق لكل مهارة، وكانت النتائج كما يلى 


\section{جدول(1)}

تتصيب وتتغيل برنامج جdobe connect

\begin{tabular}{|c|c|c|c|}
\hline \multicolumn{2}{|c|}{ نسبة الإتفاق لكوير } & \multirow[b]{2}{*}{ المهارات الفرعية } & \multirow[b]{2}{*}{ s } \\
\hline ارتباط المهارات الفرعية & أهمية كل مهارة & & \\
\hline$\% 100$ & $\% 100$ & يكتب في متصفح Google (الموقع الرسمي لشركة أدوبي). & 1 \\
\hline$\% 100$ & $\% 100$ & نختار برنامج Adobe connect من بين برامج الأدبي المتاحة. & 2 \\
\hline$\% 100$ & $\% 100$ & يقوم البرنامج ببعث إيميل يحتوي على اسم المستخدم وكلمة المرور & 3 \\
\hline$\% 100$ & $\% 100$ & 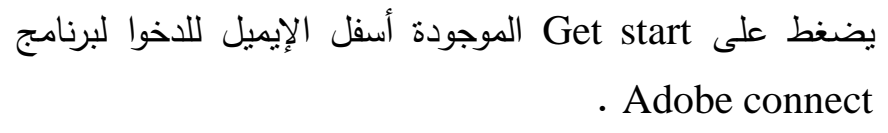 & 4 \\
\hline$\% 100$ & $\% 100$ & يكتب اسم المستخدم وكلمة المرور في المكان المخصص لها. & 5 \\
\hline
\end{tabular}

يتضح من الجدول (1) أن المهارات الفرعية للمهارة الرئيسة الأولى وهي مهارة تتصيب وتتثغيل برنامج Adobe connect قد حصلت على موافقة المحكمين جميعهم، حيث بلغت متوسط النسبة المئوية لهذه المهارة الرئيسة 100\% يرجع الباحثون ذلك لما تضمنته هذه العبارة من مهارات فرعية لازمة وضرورية قبل البدء في استخدام برنامج Adobe Connect

جدول (2)

الإعداد للمحاضرة الإلكترونية من بعد

\begin{tabular}{|c|c|c|c|}
\hline \multicolumn{2}{|c|}{ ن الإتفاق لكوير } & \multirow[b]{2}{*}{ 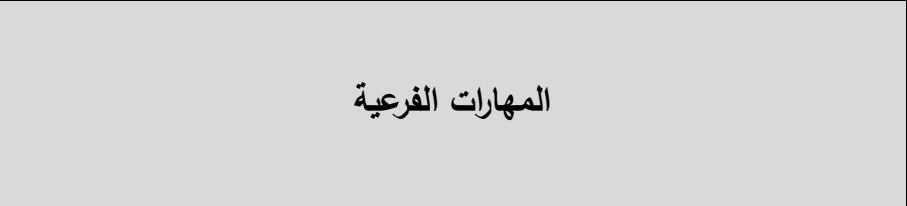 } & \multirow[b]{2}{*}{ r } \\
\hline الربتاط المهارات الفرعية & أهمية كل مهارة & & \\
\hline$\% 100$ & $\% 100$ & | إعداد محاضرة من بعد. & 1 \\
\hline$\% 100$ & $\% 100$ & يختار من الصفحة الرئيسية "Create". & 2 \\
\hline$\% 100$ & $\% 100$ & | يضغط على "Meeting".. & 3 \\
\hline$\% 100$ & $\% 100$ & "Name" يضع عنوان للمحاضرة في الخيار & 4 \\
\hline$\% 100$ & $\% 100$ & 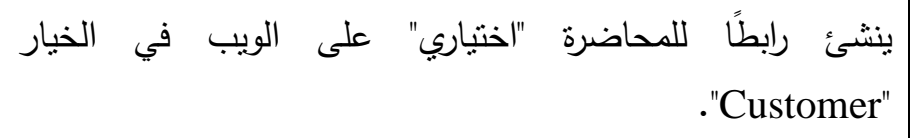 & 5 \\
\hline$\% 100$ & $\% 93.3$ & يكتب ملخصيًا للمحاضرة في المكان المخصص "Summery". & 6 \\
\hline$\% 100$ & $\% 100$ & يحدد وقت المحاضرة في الخيار Start time. & 7 \\
\hline$\% 100$ & $\% 100$ & يضبط مدة المحاضرة من الخيار Duration. & 8 \\
\hline$\% 100$ & $\% 100$ & يختار اللغة التي تستخدم في عرض المحاضرة من الخيار & 9 \\
\hline
\end{tabular}




\begin{tabular}{|c|c|c|c|}
\hline \multicolumn{2}{|c|}{ نسبة الإتفاق لكوير } & \multirow{3}{*}{ المهارات الفرعية } & \multirow{3}{*}{ s } \\
\hline ارتباط المهارات الفرعية & أهمية كل & & \\
\hline بالمهارات الرئيسة الريس & 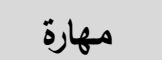 & & \\
\hline$\% 100$ & $\% 100$ & يختار من القائمة "Access" خيار الدخول لحضور المحاضرة. & 10 \\
\hline$\% 100$ & $\% 100$ & 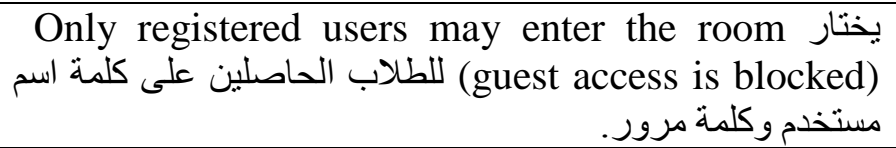 & 11 \\
\hline$\% 100$ & $\% 100$ & 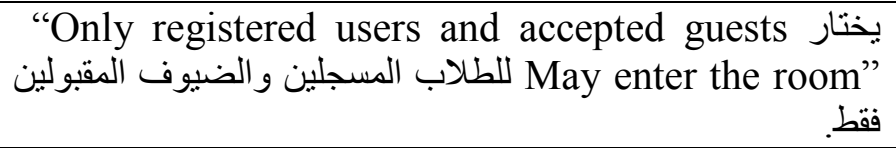 & 12 \\
\hline$\% 100$ & $\% 100$ & يختار Meeting can enter the room لأي طالب لدية URL. & 13 \\
\hline$\% 100$ & $\% 100$ & المحاضرة، على يضغط "Nits" لانتقال ل لتحديد المستهدفين لحضور & 14 \\
\hline$\% 100$ & $\% 100$ & اختيار الطلاب المستهدفين: المنين & 15 \\
\hline$\% 100$ & $\% 100$ & 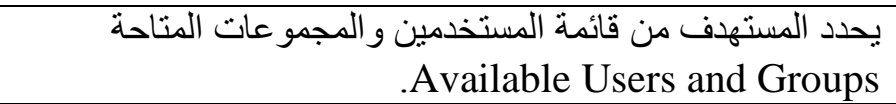 & 16 \\
\hline$\% 100$ & $\% 100$ & يضغط Add للإضافة. & 17 \\
\hline$\% 100$ & $\% 100$ & Current يحدد المستهدَف من قائمة المشتركون الحاليين.Participants & 18 \\
\hline$\% 100$ & $\% 100$ & يضغط Remove للإِز الة من القائمة. & 19 \\
\hline$\% 100$ & $\% 100$ & للطظلاب أو يضى Next لضغط إعدادات إرسال تعليمات المحاضرة & 20 \\
\hline$\% 100$ & $\% 100$ & إعداد و إرسال تعليمات المحاضرة للطلاب. & 21 \\
\hline$\% 100$ & $\% 100$ & يحدد من قائمة السرد الفئة المستهدَفة (مقدم - ضبف ـ مشارك). & 22 \\
\hline$\% 100$ & $\% 100$ & بالبريد الالكتروني المقابل ينيل Send Invitations لتفعيل خاصية الارسال & 23 \\
\hline$\% 100$ & $\% 100$ & بالبريط الإلكثروني. المقابل Do not send invitations بإلغاء الإرسال & 24 \\
\hline$\% 100$ & $\% 100$ & ينشط المربع المقابل للخيار yes لإرسال المعلومات بالتقويم. & 25 \\
\hline$\% 100$ & $\% 100$ & يضغط Previous للعودة للسابق. & 26 \\
\hline$\% 100$ & $\% 100$ & يضغط Finish لإنهاء. & 27 \\
\hline$\% 100$ & $\% 100$ & إعداد محتوى و إرساله للطلاب. & 28 \\
\hline$\% 100$ & $\% 100$ & يختار من القائمة الرئيسة الأمر Content . & 29 \\
\hline$\% 100$ & $\% 100$ & ينشئ ملف بالنقر على الأمر New folder. & 30 \\
\hline
\end{tabular}




\begin{tabular}{|c|c|c|c|}
\hline \multicolumn{2}{|c|}{ نسبة الإتفاق لكوير } & \multirow{3}{*}{ 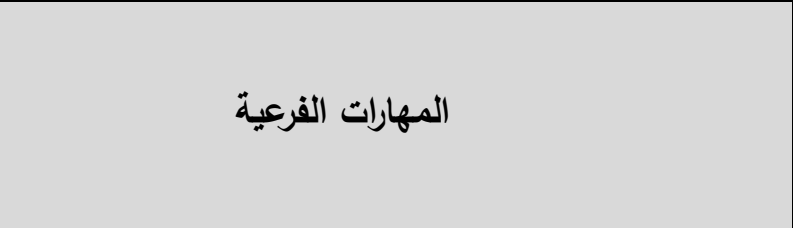 } & \multirow{3}{*}{ s } \\
\hline ارتباط المهارات الفرعية & أهمية كل & & \\
\hline بالمهارات الرئيسة & 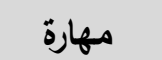 & & \\
\hline$\% 100$ & $\% 100$ & يكتب اسم الملف. & 31 \\
\hline$\% 100$ & $\% 100$ & يكتب ملخص لمحتوي الملف. & 32 \\
\hline$\% 100$ & $\% 100$ & ينقر على Save للحفظ. & 33 \\
\hline$\% 100$ & $\% 100$ & إعداد محتوى وإرساله للطلاب. & 34 \\
\hline$\% 100$ & $\% 100$ & ينقر على New Content لإضافة محتوى. & 35 \\
\hline$\% 100$ & $\% 100$ & يدرج المحتوى عن طريق الضغط على Choose file. & 36 \\
\hline$\% 100$ & $\% 100$ & يكتب عنوان المحتوى Title. & 37 \\
\hline$\% 100$ & $\% 100$ & يكتب ملخص للمحتوي Summary . & 38 \\
\hline$\% 100$ & $\% 100$ & انقر Save للحفظ. & 39 \\
\hline$\% 100$ & $\% 100$ & ينقر E-mail link لإرسال المحتوى. & 40 \\
\hline$\% 100$ & $\% 100$ & يكتب البريد الإلكتروني للطالب. & 41 \\
\hline$\% 100$ & $\% 100$ & 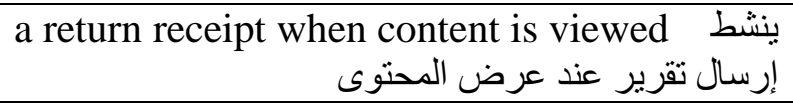 & 42 \\
\hline$\% 100$ & $\% 100$ & حذف محتوى. & 43 \\
\hline$\% 100$ & $\% 100$ & يختار My content من القائمة الرئيسة. & 44 \\
\hline$\% 100$ & $\% 100$ & يحدد الملف المر اد حذفة بوضع علامة ل ل امام الملف. & 45 \\
\hline$\% 100$ & $\% 100$ & إعداد مجمو عة جديدة وإضافة طالب لها. & 46 \\
\hline$\% 100$ & $\% 100$ & ينقر فوق Delete للحذف. & 47 \\
\hline$\% 100$ & $\% 100$ & يضغط على Administration من القائمة الرئيسة. & 48 \\
\hline$\% 100$ & $\% 100$ & يختار Users and group & 49 \\
\hline$\% 100$ & $\% 100$ & يضغط على New group. & 50 \\
\hline$\% 100$ & $\% 100$ & يكتب اسم الطالب First Name. & 51 \\
\hline$\% 100$ & $\% 100$ & يكتب لقب الطالب Last Name. & 52 \\
\hline$\% 100$ & $\% 100$ & يكتب البريد الإلكتروني للطالب E-mail . & 53 \\
\hline$\% 100$ & $\% 100$ & يكتب الرقم السري New Password . & 54 \\
\hline
\end{tabular}




\begin{tabular}{|c|c|c|c|}
\hline \multicolumn{2}{|c|}{ نسبة الإتفاق لكوير } & \multirow{3}{*}{ المهارات الفرعية } & \multirow{3}{*}{ r } \\
\hline ارتباط المهارات الفرعية & أهمية كل & & \\
\hline بالمهارات الرئيسة & 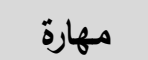 & & \\
\hline$\% 100$ & $\% 100$ & | يعيد الرقم السري Retype Password. & 55 \\
\hline$\% 100$ & $\% 100$ & ينقر "Finish" للأنهاء. & 56 \\
\hline$\% 100$ & $\% 100$ & | إضافة طالب إلى محاضرة. & 57 \\
\hline$\% 100$ & $\% 100$ & ينشئ مجمو عة بالضغط على New grub. & 58 \\
\hline$\% 100$ & $\% 100$ & | يكتب اسم للمجمو عة Name. & 59 \\
\hline$\% 100$ & $\% 100$ & | يكتب وصف للمجمو عة Description. & 60 \\
\hline$\% 100$ & $\% 100$ & ينقز على Next لإنهاء. & 61 \\
\hline$\% 100$ & $\% 100$ & | ينقر على الطالب المضاف من المسجلين. & 62 \\
\hline$\% 100$ & $\% 100$ & ينقر Add للإضافة. & 63 \\
\hline$\% 100$ & $\% 100$ & | ينقر على Finish للإنهاء. & 64 \\
\hline
\end{tabular}

يتضـح من الجدول (2) أن المهارة الرئيسة الثانيـة وهي إعداد المحاضرات الالكترونية من بعد،

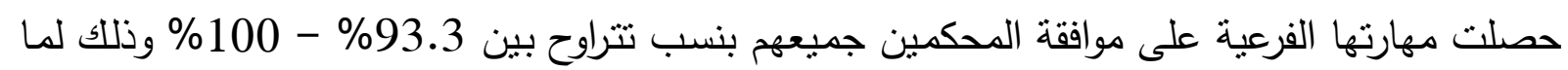
تضمنه هذه المهارة من مهارات فرعية وضرورية لإعداد المحاضرة الإكترونية.

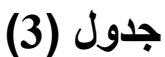

إدارة المحاضرة الإلكترونية من بعد

\begin{tabular}{|c|c|c|c|}
\hline \multicolumn{2}{|c|}{ نسبة الإتفاق لكوير } & \multirow[b]{2}{*}{ المهارات الفرعية } & \multirow[b]{2}{*}{ r } \\
\hline بارتباط المهارات الفرعية & أهمية كل & & \\
\hline$\% 100$ & $\% 100$ & الدخول إلى المحاضرة من بعد. & 1 \\
\hline$\% 100$ & $\% 100$ & ينقر على Home من القائمة الرئيسة. & 3 \\
\hline$\% 100$ & $\% 100$ & اليومي، الأسبو عي). My calendar لمعرفة تقويم المحاضر ات (النشط، & 4 \\
\hline$\% 100$ & $\% 100$ & يختار My meetings لظهور قائمة المحاضرات. & 5 \\
\hline$\% 100$ & $\% 100$ & ينقر على Open عند المحاضرة من القائمة للاخول للمحاضرة. & 6 \\
\hline$\% 100$ & $\% 100$ & يختار القالب المناسب من القو الب الموجودة. & 7 \\
\hline$\% 100$ & $\% 100$ & مشاركة الفيديو عبر الويب. & 8 \\
\hline$\% 100$ & $\% 100$ & 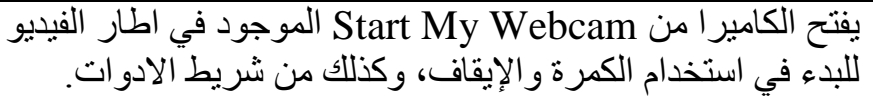 & 9 \\
\hline
\end{tabular}




\begin{tabular}{|c|c|c|c|}
\hline \multicolumn{2}{|c|}{ ن الإتفاق لكوير } & \multirow{3}{*}{ المهارات الفرعية } & \multirow{3}{*}{ r } \\
\hline ارتباط المهارات الفرعية & أهمية كل & & \\
\hline بالمهارات الرئيسة & 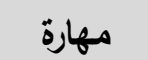 & & \\
\hline$\% 100$ & $\% 100$ & يضغط على الكامير ا من شريط الأدو ات للبدء و الايقاف. & 10 \\
\hline$\% 100$ & $\% 93.3$ & يستخدم السحب والافلات في إطار الفيديو لتغيير مكان الفيديو. & 11 \\
\hline$\% 100$ & $\% 100$ & ينقر على Pods في القائمة الرئيسة. & 12 \\
\hline$\% 100$ & $\% 100$ & يختار من القائمة المنسدلة Share. & 13 \\
\hline$\% 100$ & $\% 100$ & مشاركة شاشة الكمبيوتر في المحاضرة. & 14 \\
\hline$\% 100$ & $\% 100$ & الثنقاشة على Share my screen من القائمة المنسِلة لمشاركة & 15 \\
\hline$\% 100$ & $\% 100$ & -يضغط على share لمشاركة الثانشة. & 16 \\
\hline$\% 100$ & $\% 100$ & ـ يختار من الاخرينة الثاشة المشاركة - ( الكاميرة ـ الصوت الدردشة & 17 \\
\hline$\% 100$ & $\% 100$ & ينقر على Stop sharing للإنهاء & 18 \\
\hline$\% 100$ & $\% 100$ & 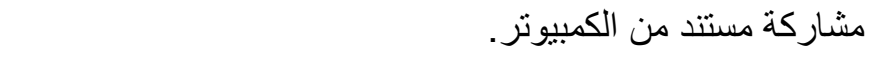 & 19 \\
\hline$\% 100$ & $\% 100$ & ينقر على Share Document لمشاركة مستند من الكمبيوتر. & 20 \\
\hline$\% 100$ & $\% 93.3$ & يختار مكان وجود الملف. & 21 \\
\hline$\% 100$ & $\% 100$ & ينقر على .Browse my computer. & 22 \\
\hline$\% 100$ & $\% 100$ & يختار الملف المطلوب ويضغط على Open. & 23 \\
\hline$\% 100$ & $\% 100$ & يضغط للتشغيل الملف. play. & 24 \\
\hline$\% 100$ & $\% 100$ & 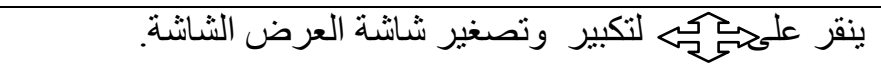 & 25 \\
\hline$\% 100$ & $\% 100$ & يستخدم ل للتوضيح أثناء الشرح. & 26 \\
\hline$\% 100$ & $\% 100$ & ينقر Stop shareing للإنهاء. & 27 \\
\hline$\% 100$ & $\% 100$ & مشار كة ملفات في المحاضرة. & 28 \\
\hline$\% 100$ & $\% 100$ & ينقر على Upload file لرفع ملف. & 29 \\
\hline$\% 100$ & $\% 100$ & ينقز على Browse my computer. & 30 \\
\hline$\% 100$ & $\% 100$ & يختار الملف المطلوب ويضغط على Open. & 31 \\
\hline$\% 100$ & $\% 100$ & ينقر على Download file لتنزيل الملفات. & 32 \\
\hline$\% 100$ & $\% 100$ & ضبط لوحة الإعلانات. & 33 \\
\hline
\end{tabular}




\begin{tabular}{|c|c|c|c|}
\hline \multicolumn{2}{|c|}{ نسبة الإتفاق لكوير } & \multirow{3}{*}{ المهارات الفرعية } & \multirow{3}{*}{ s } \\
\hline ارتباط المهارات الفرعية & أهمية كل & & \\
\hline 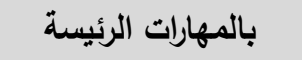 & 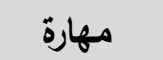 & & \\
\hline$\% 100$ & $\% 93.3$ & يكتب في المكان المخصص للكتابة الإعلان. & 34 \\
\hline$\% 100$ & $\% 100$ & يغير حجم الخط في القائمة المنسدلة. & 35 \\
\hline$\% 100$ & $\% 100$ & ينقر T لتغيير نمط الخط. & 36 \\
\hline$\% 100$ & $\% 93.3$ & 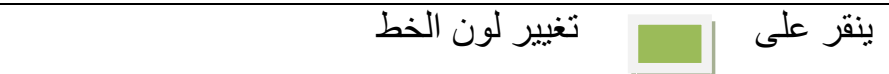 & 37 \\
\hline$\% 100$ & $\% 100$ & 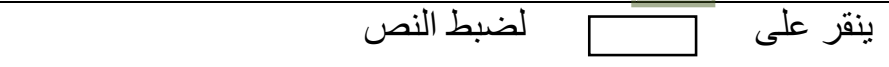 & 38 \\
\hline$\% 100$ & $\% 100$ & ينقر من القائمة المنسدلة على Email note لإرسال الاعلان على & 39 \\
\hline$\% 100$ & $\% 100$ & إظهار حالة الطالب. إلب & 40 \\
\hline$\% 100$ & $\% 100$ & ينقرة من القائمة المنسدلة على New note للوحة إعلانات & 41 \\
\hline$\% 100$ & $\% 100$ & ينقر منًا. القائمة المنسدلة على Raise hand لطلب المداخلة & 42 \\
\hline$\% 100$ & $\% 100$ & ينقر على Agree لإظهار الإعجاب. & 43 \\
\hline$\% 100$ & $\% 100$ & ينقر على Agree Agree ه لإظهار الاعجاب . & 44 \\
\hline$\% 100$ & $\% 100$ & ينقر على Speak softeللتعبير ضعف الصوت للمتحدث. & 45 \\
\hline$\% 100$ & $\% 100$ & ينقر على Speak louder للتعبير عن ارتفاع الصوت للمتحدث. & 46 \\
\hline$\% 100$ & $\% 100$ & ينقر على Slow down للتعبير عن ان الصوت بطي . & 47 \\
\hline$\% 100$ & $\% 100$ & ينقر على Laughter للتعبير عن الفرح & 48 \\
\hline
\end{tabular}

ويتضح من الجدول (3) أن المهارة الرئيسة الثالثة وهي إدارة المحاضرات الإلكترونية من بعد، قد

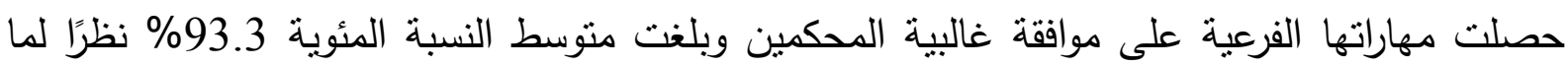
تضمنته من مهارات فرعية قد يراها البعض بأنها غير مهمة.

3-التوصل إلى الصورة النهائية لقائمة المعايير الخاصة بتطوير المحاضرات الاكترونية:

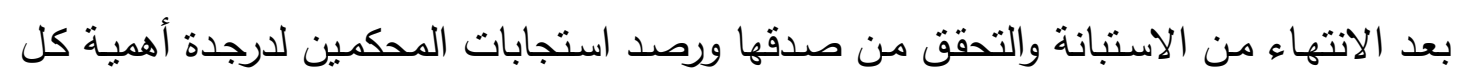

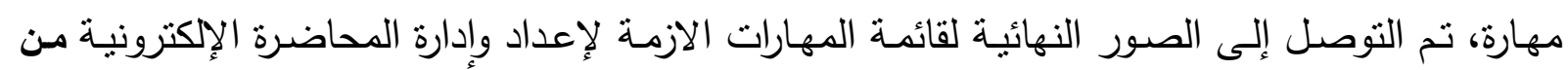

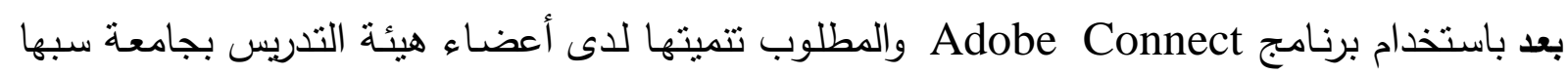

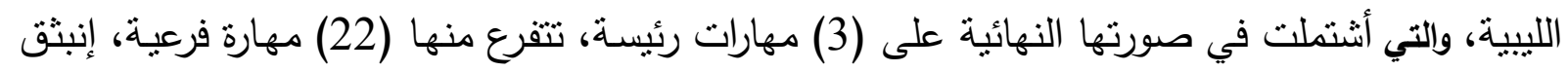
منها (105) مؤشر لأداء المهارات الفرعية كما موضح في فئه الملدق. 
أسفرت نتائج البحث الحالي عن الوصول لقائمة بمهارات تطوير المحاضرات الإلكترونية وإدارتها

من بعد والمطلوب تتميتها لدى أعضاء هيئة التدريس بجامعة سبها الليبية.

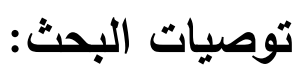

توصل الباحثُن من خلال نتائج البحث، التي تم الحصول عليها ومناقشتها إلى التوصيات التالية: - الاستفادة من قائمة المهارات التي أعدها الباحثون في تتمية مهارات المحاضرة الإكترونية وإدارتها من بعد.

- تدريب أعضاء هيئة التدريس على استخدام برنامج Adobe Connect.

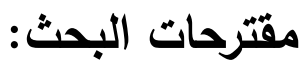

يقترح الباحثون إجراء البحوث التالية:

- إعداد برنامج تدريبي لإكساب أعضاء هيئة التدريس بالمدارس تتمية مهارات إعداد الدروس -

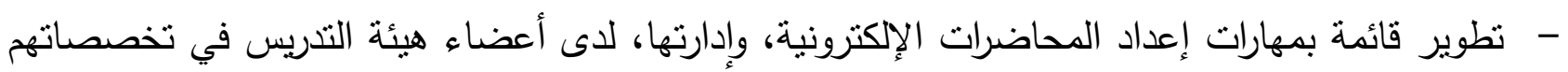

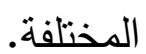

\begin{abstract}
:
This research aimed to reach a list of the skills of developing and managing Electronic lecturers remotely among Faculty Staff Members at the Libyan University of Sebha. In order to achieve that, the researchers have followed the analytic descriptive approach to identify the skills of developing and managing Electronic lecturers remotely by using adobe connect program. Then the researchers have transformed it to a questionnaire in order to explore the views of the experts and specialists of education technology. The research sample consisted of (15) arbitrators who are specialized in education Technology. Then the researchers have collected, analyzed and processed the data statistically by using the appropriate statistical methods. The results of the research leads to reaching a final list of the skills of developing and managing Electronic lecturers remotely by using Adobe connect program, consisting of (3) main skill, and (22) sub-skills.
\end{abstract}

Key Words: Skill- Electronic Lectures - Distance Learning. 


\section{قائمة المراجع}

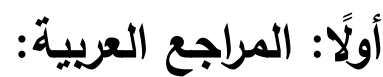

أماني محمد عوض، الثحات سعد عتمان(2007). مفاهيم وأساسيات في تكنولوجيا التعليم، الطبعة الاولى

جمال عبد الناصر الثرقاوي، السعيد السعيد محمد الرزاق، مجلة التعليم الإلكتروني، جامعة المنصورة العدد السادس، 2010/1/1م.

حسين على آدم بغزالة (2012). دراسة التعليم الإلكتروني ودورة في تطوير التعليم العالي في ليبيا، ورقة منشورة في المؤتمر العربي حول التعليم العالي وسوق العمل، طرابلس (ليبيا).

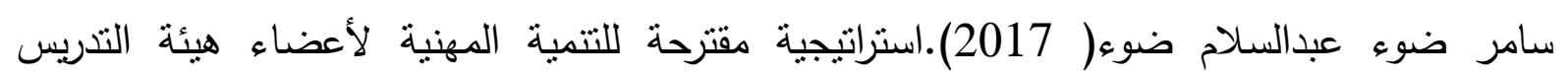
بالجامعات الليبية في ضوء خبرات بعض الدول المتقدمة، رسالة دكتوراه كلية التربية، جامعة دمياط. الغريب زاهر أسماعيل (2009). التعليم الالكتروني من التطبيق الى الاحتراف والجودة. عالم الكتب، القاهرة.

فريحة أبوبكر أبو عمود (2010). التعلم الالكتروني في الجامعات الليبية الواقع الروئة المستقلية، ورقة منشورة في المؤتمر العربي حول التعليم العالي وسوق العمل، طرابلس (ليبيا). محمد راضي الكبيسي، أيمن أبو غازي (2013م). بناء نظام التعليم الإلكتروني باستخدام الفصل فرلئل

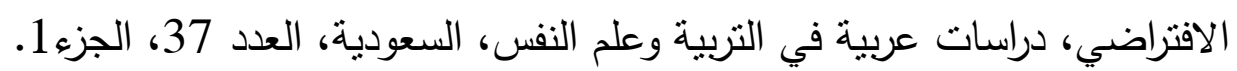
محمد عطيه خميس (2009). تكنولوجيالتعليم والتعلم، القاهرة، الطبعة الاولى، دار السحاب للطباعة الطبه والنشر والتوزيع.

محمد محمود الحيلة. (2008). مهارات التدريب الصفي. عمان: دار المسيرة للنشر والتوزيع والطباعة.

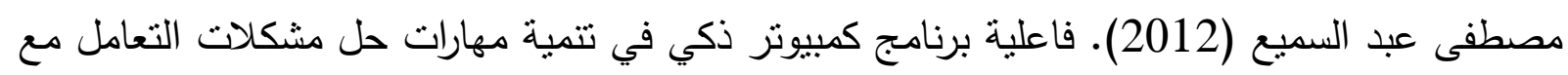

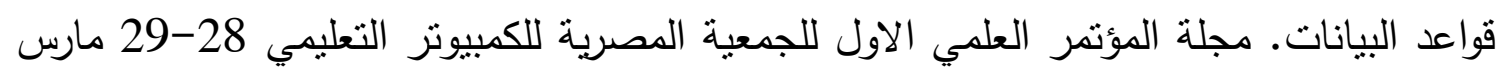

$$
\text { 2012م، بور سعيد. }
$$

مصطفى عبد العظيم الطيب (2010). انعكاسات تقنية المعلومات على العملية التعليمية من وجهة نظر أساتذة الجامعات، ورقة منشورة في المؤتمر العربي حول التعليم العالي وسوق العمل، طرابلس السكان

منى محمد الجزار (2014): فاعلية نظم مستودع لكائنات التعلم الرقمية في ضوء المعايير التربوية والاتجاهات التعليمية في مجال تقنيات التعلم لدى طالبات تكنولوجيا التعليم بالرياض، الجمعية 


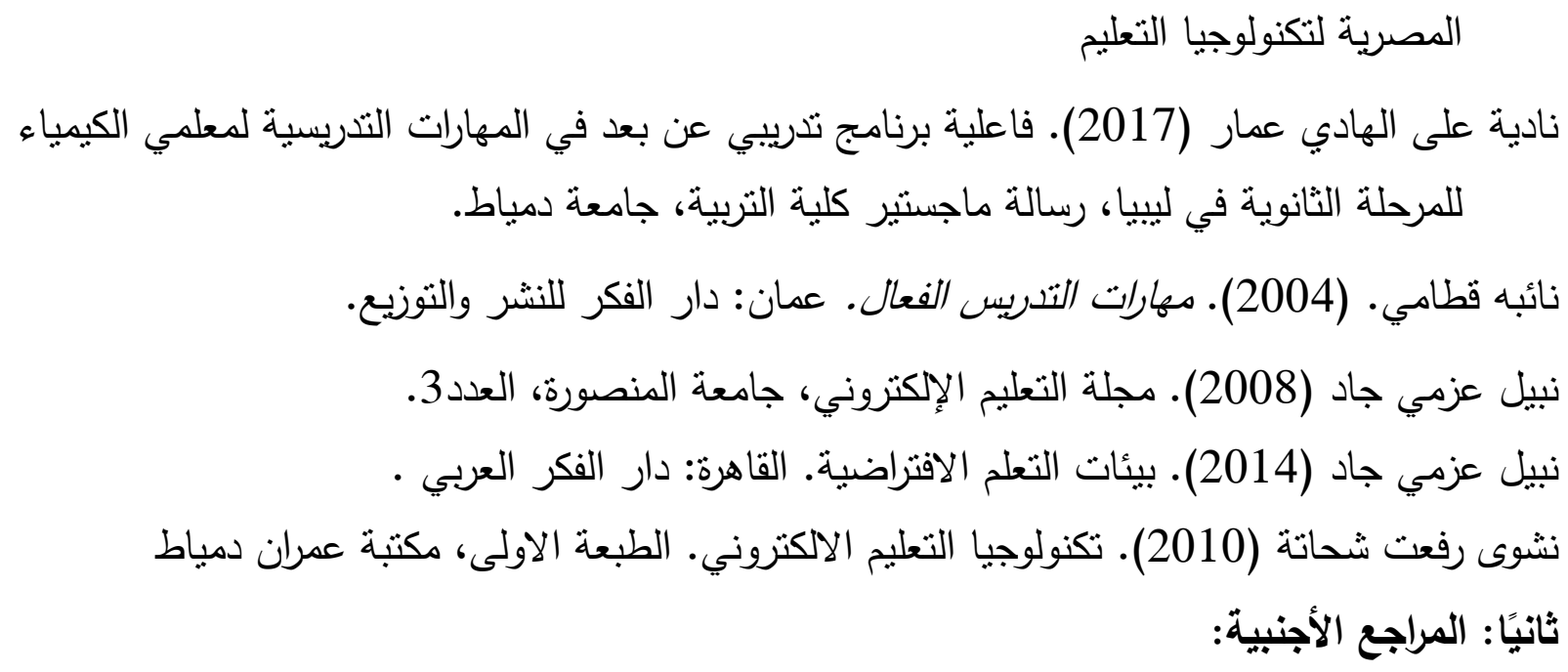

Akansha Arora : Using E-Learning Technologies To Improve Educational Quality Of Language Teaching , September 12, 2015 available at : https://elearningindustry.com/using-e-learningtechnologies-improve-educationalquality-language-teaching.

Baron, T. (2000). Getting IT Support for E-Learning. Training and Development, 54(12), 3237.

Cantoni, V., Cellario,M., and Porta,M.(2004). Perspectives and Challenges in E-learning: Towards Natural Interaction Paradigms. Journal of Visual Languages and Computing, $15,333-345$.

Gordon,J.(2003). E-learning Tagged as Best Corporate IT Investment. E-learning, 4(1),8.

Gülbahar, Y. \& Alper, A. (2012). Discussion of e-Learning Strategies for Moderation and Assessment. Future-Learning 2012 - IV. Uluslararası Gelecek İçin Öğrenme Alanında Yenilikler Konferansı: e-Öğrenme, 14-16 Kasım 2012, İstanbul, Türkiye.

Guo, P. J., Kim, J., \& Rubin, R. (2014). How video production affects student engagement: An empirical study of MOOC videos. Retrieved from http://pgbovine.net/publications/edX-MOOCvideo-production-andengagement_LAS2014.pdf.

Ismail, Othman Atta(2018): Building the digital lecture and investing it in elearning : applied study.

Jadin, tn Gruber, A, A\& Botanic B, 2009 Learning with E-lectures the meaning of learning strategies educational Technology\& Society, 12(3), 282-288

Shweta Sharma, Shruti Guota (2012). The Virtual Classroom: The Role of ICT in Open and Distance Learning, IJCCET International Journal of Computer. Communication and Emerging Technology Volume 1, Issue 1, April 2012, www.IJCCET.com

Ninoriya, S., Chowan, P., Metiram, B., \& VJTI, M. (2011). CMS, LMS and LCMS for eLearning. IJCSIInternational Journal of Computer Science, 8(2), 644-647. 
ملحق

القائمة النهائية بمهارات تطويرالمحاضرات الإلكترونية وإدارتها من بعد لاى

أعضاء هيئة التدريس بجامعة سبها الليبية.

\author{
إعداد \\ أيوب سالم محمد أحمد الحاج على \\ باحث ماجستير تخصص تكنولوجيا التعليم \\ قسم تكنولوجيا التعليم - كلية التربية - جامعة دمياط
}

$$
\text { أ.د أماني محمد عوض. }
$$

أستاذ تكنولوجيا التعليم ووكيل الكلية لثئون خدمة المجتمع وتتمية البيئة ومدير مركز إنتاج المقررات الإككترونية بجامعة دمياط
أ.د الثحات سعد عتمان.

أستاذ تكنولوجيا التعليم ووكيل الكلية لثئون التعليم والطلاب، ومدير وحدة التعليم الإلكتروني بجامعة دمياط

1442-2019 


\section{قائمة بمهارات تطوير المحاضرات الإكترونية، وإدارتها من بعد، المطلوب تنميتها لاى أعضاء هيئة}

\section{التدريس بجامعة سبها الليبية.}

\begin{tabular}{|c|c|}
\hline Adobe connect الاخول لبرنامج & المهارة الرئيسة الأولى: \\
\hline مؤثرات الأداء للمهارات الفرعية & 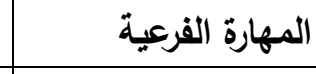 \\
\hline 1- يكتب في منصفح Google (الموقع الرسمي لشركة الأدوبي). & \multirow{5}{*}{$\begin{array}{l}\text { برنامج تحميل وتثبيت } 1 \\
\text { Adobe } \\
\text { connect }\end{array}$} \\
\hline 2- يختار برنامج Adobe connect من بين برامج شركة الأدوبي المتاحة. & \\
\hline 3- يقوم بملء النموذج الخاص بالبرنامج. & \\
\hline 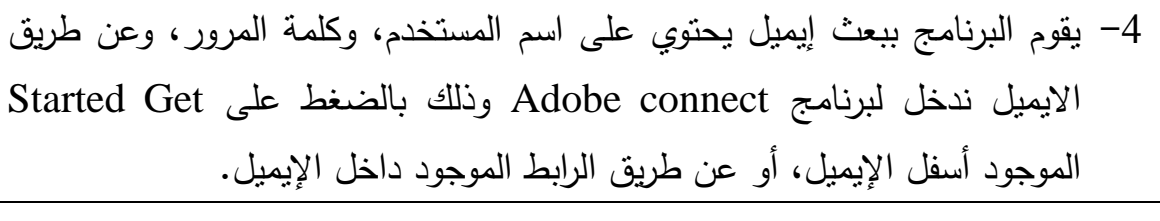 & \\
\hline 5- يكتب اسم المستخدم وكلمة المرور في المكان المخصص. & \\
\hline \multicolumn{2}{|c|}{ Adobe connect المهارة الرئيسة الثانية: إعداد المحاضرة الإكترونية من بعد باستخدام برنامج } \\
\hline 1 - يختار من الصفحة الرئيسة Create. & \multirow{13}{*}{ 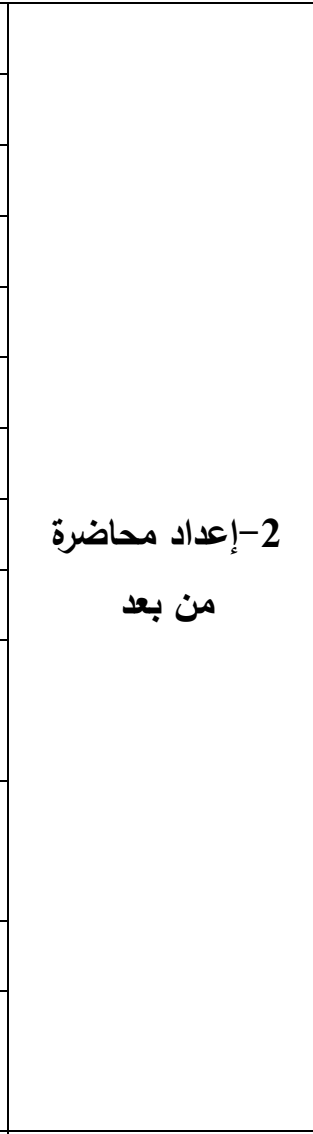 } \\
\hline 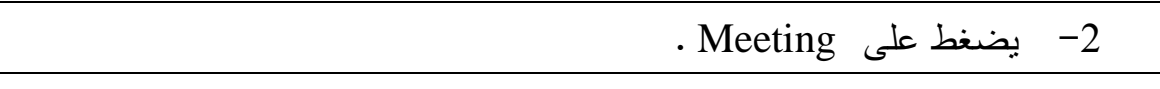 & \\
\hline 3- يضع عنوان للمحاضرة في الخيار Name. & \\
\hline 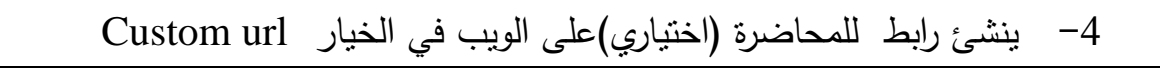 & \\
\hline 5- يكتب ملخصاً للمحاضرة في المكان المخصص Summary. & \\
\hline 6- يحدد وقت المحاضرة في الخيار Start time & \\
\hline 7 - يضبط مدة المحاضرة من الخيار Duration & \\
\hline 8- يختار اللغة التي تستخدم في عرض المحاضرة من الخيار Language. & \\
\hline 9- يختار من القائمة "Access" خيار الدخول لحضور المحاضرة. & \\
\hline 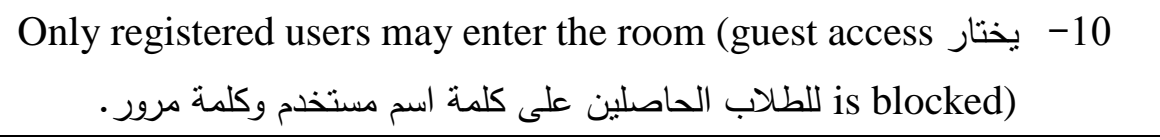 & \\
\hline $\begin{array}{c}\text { "Only registered users and accepted guests May enter يختار المسلين والضيوف المقبولين فقط. 1he room" } \\
\text { "للطاب th" }\end{array}$ & \\
\hline 12- يختار Meeting can enter the room لأي طالب لدية.URL. & \\
\hline 13- يضغط على Next" للإنهاء. "Finish" & \\
\hline $\begin{array}{c}\text { Available Users يحدد المستهدَف من قائمة المستخدَمين والمجموعات المتاحة } \\
\text { and Groups }\end{array}$ & \multirow{4}{*}{ - 2- - اختيار الطلاب } \\
\hline 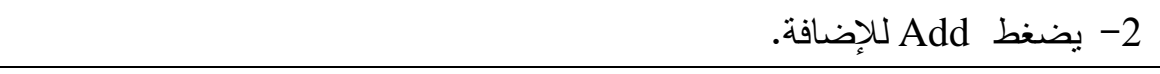 & \\
\hline 3- يحدد المستهدَف من قائمة المشتركون الحاليين Participants Current & \\
\hline 4- يضغط Remove للإزالة من القائمة. & \\
\hline
\end{tabular}




\begin{tabular}{|c|c|}
\hline مؤشرات الأداء للمهارات الفرعية & 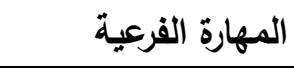 \\
\hline 5- يضغط على Next لضبط إعدادات ارسال تعليمات المحاضرة للطلاب، أو يضغط & \\
\hline 1- يحدد من قائمة السرد الفئة المستهدَفة (مقدم - ضيف - مشارك). & \multirow{6}{*}{$\begin{array}{c}\text { 3-3 إعداد وارسال } \\
\text { المليمات }\end{array}$} \\
\hline 2- ينشط المربع المقابل Send Invitations & \\
\hline 3- ينشط المربع المقابل Do not send invitations لإلغاء الارسال بالبريد & \\
\hline 4- ينشط المربع المقابل للخيار yes لإرسال المعلومات بالتقويم. & \\
\hline 5- يضغط Previous للعودة للسابق. & \\
\hline 6- يضغط Finish لإنهاء. & \\
\hline 1- يختار من القائمة الرئيسة الأمر Content . & \multirow{5}{*}{ 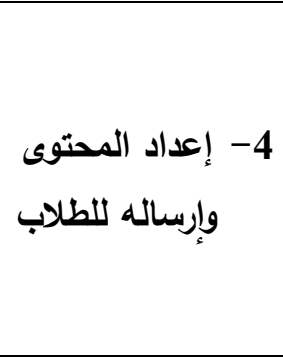 } \\
\hline 2- ينشي ملف بالنقر على الأمر New folder. & \\
\hline 3- يكتب اسم الملف. & \\
\hline 4- يكتب ملخص لمحتوي الملف. & \\
\hline 5- ينقر على Save للحفظ. & \\
\hline 1 - ينقر على New Content لإضافة محتوى. & \multirow{8}{*}{-5 - إعداد المحتوى وإرساله للطلاب } \\
\hline 2- يدرج المحتوى عن طريق الضغط على Choose file. & \\
\hline 3- يكتب عنوان المحتوى Title. & \\
\hline 4- يكتب ملخص للمحتوي Summary . & \\
\hline Save انحفظ. Sa & \\
\hline 6- ينقر E-mail link لإرسال المحتوى. & \\
\hline 7- يكتب البريد الالكتروني للطالب. & \\
\hline 8- ينشط مرض المحتوى & \\
\hline 1- يختار My content من القائمة الرئيسة. & \multirow{3}{*}{ 6- حذف محتوى } \\
\hline 2- يحدد الملف المراد حذفة بوضع علامة ل ل امام الملف. & \\
\hline 3- ينقر فوق Delete للحذف. & \\
\hline 1- يضغط على Administration من القائمة الرئيسية. & \multirow{2}{*}{ - - إعداد مجموعة } \\
\hline 2- يختار Users and group & \\
\hline
\end{tabular}




\begin{tabular}{|c|c|}
\hline 3- يضغط على New group. & \multirow[t]{3}{*}{ طالب لها. } \\
\hline 4- يكتب اسم الطالب First Name. & \\
\hline 5- يكتب لقب الطالب Last Name. & \\
\hline مؤشرات الأداء للمهارات الفرعية & المهارة القرعية \\
\hline 6- يكتب البريد الإلكتروني للطالب E-mail . & \\
\hline 7- يكتب الرقم السري New Password . & \\
\hline 8- يعيد الرقم السري Retype Password. & \\
\hline 9- ينقر "Finish" للأنهاء. & \\
\hline 1- ينشئ مجموعة بالضغط على New grub. & \multirow{7}{*}{ 8- إضافة طالب } \\
\hline 2- يكتب اسم للمجموعة Name. & \\
\hline 3- يكتب وصف للمجموعة Description. & \\
\hline 4- ينقر على Next لإنهاء. & \\
\hline 5- ينقر على الطالب المضاف من المسجلين. & \\
\hline 6- ينقر Add للإضافة. & \\
\hline 7- ينقر على Finish للإنهاء & \\
\hline
\end{tabular}

Adobe connect المهارة الرئيسة الثالثة:إدارة المحاضرة الإكترونية من بعد باستخدام برنامج

\begin{tabular}{|c|c|}
\hline 1- ينقر على Home من القائمة الرئيسة. & \multirow{5}{*}{ 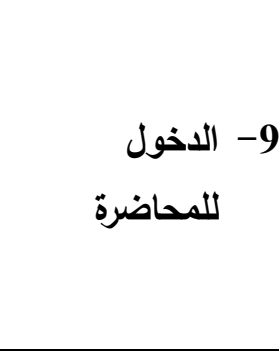 } \\
\hline 2- يختار My calendar لمعرفة تقويم المحاضرات (النشط، اليومي، الأسبوعي) & \\
\hline 3- يختار My meetings لظهور قائمة المحاضرات. & \\
\hline 4- ينقر على Open عند المحاضرة من القائمة للاخول للمحاضرة. & \\
\hline 5- يختار القالب المناسب من القوالب الموجودة. & \\
\hline 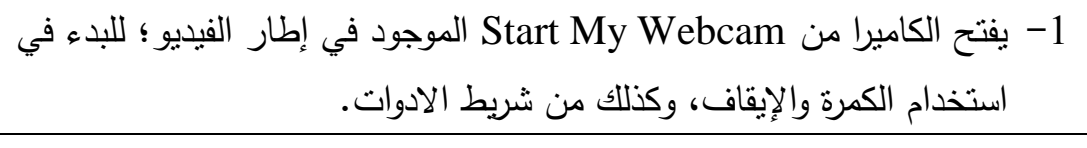 & \multirow{5}{*}{ الويبو عبر } \\
\hline 2- يضغط على الكاميرا من شريط الأدوات للبدء والايقاف. & \\
\hline 3- يستخدم السحب والإفلات في إطار الفيديو لتغيير مكان الفيديو . & \\
\hline 4- ينقر على Pods في القائمة الرئيسة. & \\
\hline 5- يختار من القائمة المنسدِلة Share. & \\
\hline 1- ينقر على Share my screen من القائمة المنسدِلة لمشاركة الثشاشة & \multirow{3}{*}{ 11 - مشاشة الكمبيوتر } \\
\hline 2- يضغط على share لمشاركة الثشاشة. & \\
\hline 3- يختار من قائمة الثاشة الششاركة - ( الكاميرا - الصوت الدردشة - مشاركة & \\
\hline
\end{tabular}




\begin{tabular}{|c|c|}
\hline 4- ينقر على Stop sharing للإنهاء & \\
\hline 1- ينقر على Share Document لمشاركة مستتد من الكمبيوتر . & \multirow{3}{*}{ 12-12 - مستتد من مشاركة } \\
\hline 2- يختار مكان وجود الملف. & \\
\hline 3- ينقر على.Browse my computer. & \\
\hline
\end{tabular}

\begin{tabular}{|c|c|}
\hline مؤشرات الأداء للمهارات الفرعية & المهارة الفرعية \\
\hline 1- يختار الملف المطلوب ويضغط على Open. & \multirow{5}{*}{ 13- مستتد من مشاركة } \\
\hline 2- يضغط play للتشغيل الملف. & \\
\hline 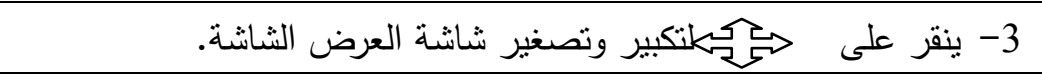 & \\
\hline 4- يستخدم ل للتوضيح أثناء الشرح. & \\
\hline 5- ينقر Stop shareing للإنهاء. & \\
\hline 1- ينقر على Upload file لرفع ملف. & \multirow{4}{*}{ 14- - الملفات في مشاركة } \\
\hline 2- ينقر على.Browse my computer. & \\
\hline 3- يختار الملف المطلوب ويضغط على Open. & \\
\hline 4- ينقر على Download file لتنزيل الملفات. & \\
\hline 1 -يكتب في المكان المخصص الاعلان للكتابة. & \multirow{6}{*}{$\begin{array}{c}\text { الإعلانات } \quad \text { ضبط لوحة } \quad \text { ل15 } \\
\text { Notes }\end{array}$} \\
\hline 2- يغير حجم الخط في القائمة المنسِلة. & \\
\hline 3- ينقر T لتغيير نمط الخط. & \\
\hline 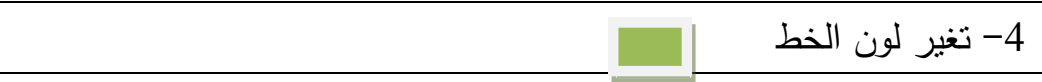 & \\
\hline 5- ينقا & \\
\hline 6- ينقر من القائمة المنسدلة على Email note لإرسال الإعلان على البريد & \\
\hline 1- ينقر من القائمة المنسدلة على New note للوحة إعلانات جديدة. & \multirow{9}{*}{ 16- - إظهار حالة } \\
\hline 2- - ينقر من القائمة المنسدلة على Raise hand لطلب المداخلة صوتيًّا. & \\
\hline 3- ينقز على Agree لإظهار الإعجاب. & \\
\hline 4- ينقر من القائمة المنسدلة على New note للوحة إعلانات جديدة. & \\
\hline 5- ينقر من القائمة المنسدلة على Raise hand لطلب المداخلة صوتيًا. & \\
\hline 6- ينقر على Agree لإظهار الإعجاب. ل & \\
\hline 7- ينقر على Agree Agree & \\
\hline 8- ينقر على Speak softe للتعبير ضعف الصوت للمتحدث. & \\
\hline 9- ينقر على Speak louder للتعبير عن ارتفاع الصوت للمتحدث & \\
\hline
\end{tabular}




$$
\begin{aligned}
& \text { 10-ينقر على Slow down للتعبير عن ان الصوت بطي. } \\
& \text { 11- ينقز على Laughter للتعبير عن الفرح. } \\
& \text { 12- ينقر Applause للتحية. }
\end{aligned}
$$

